\title{
A Flexible Modeling Framework to Estimate Interregional Trade Patterns and Input-Output Accounts
}

\author{
Patrick Canning, Economic Research Service, US Department of Agriculture \\ Zhi Wang, School of Computational Sciences, George Mason University
}

(First Draft-Do not quote)

\begin{abstract}
This study implements and tests a mathematical programming model to estimate interregional, interindustry transaction flows in a national system of economic regions based on an interregional accounting framework and initial information of interregional shipments. A complete national IO table, regional sectoral data on gross output, value-added, exports, imports and final demand are used as inputs to generate an interregional input-output system that reconciles regional market data and interregional transactions. The analytical and empirical properties of the model are discussed in detail. The model is tested by a 3-region 10-sector example against data aggregated from the version 4 GTAP database. It shows that the model has remarkable capacity to discover the true interregional trade pattern from highly distorted initial estimates. The paper also discusses an application of the model to estimate an interregional input-output account for the US economy based on the BEA 1997 national benchmark IO table and detailed state level data from the 1997 economic Census and other sources.
\end{abstract}

April 30, 2003

Paper prepared for presentation at the Sixth Annual Conference on Global Economic Analysis, June 12-14, Scheveningen, The Netherlands. 


\section{Introduction}

A major obstacle in regional economic analysis is the lack of consistent, reliable regional data, especially data on interregional trade and inter-industrial transactions. Despite decades of efforts by regional economists, data analogous to national input-output accounts and international trade accounts, which have become increasingly available to the public today, still are generally not available even for well defined sub-national regions in many developed countries. Therefore, regional economists have had to develop various non-survey methods to estimate such data.

This paper present a flexible modeling framework to estimate interregional trade flows and input-output accounts for a national system of economic regions. The approach employed simultaneously optimizes the information gained by data available from different sources in a consistent interregional accounting system. Typically, data from different statistical sources have substantial gaps and inconstancies that preclude routine solutions from being obtained without modification. Our approach allows all relevant information to be incorporated in the data adjustment process in an internally consistent manner with an objective ranking of their relative reliabilities, and is also flexible enough in the model specification to use useful information from all possible sources. While the applications of this modeling framework may be quite broad, its design has been specifically targeted to the problem of developing spatial enhancements to a national input-output account for economies with well-defined economic sub-regions.

This paper is organized as follows. Section II specifies the modeling framework and discusses its theoretical and empirical properties. Section III tests the model by using a 3-region, 10-sector data set aggregated from the version 4 GTAP database. Test results from seven experiments were evaluated against eight Mean Absolute Percentage Error indexes. Section IV 
discusses the empirical issues involved in applying such a modeling framework to estimate a 51region (50 states plus Washington DC), 38 sector inter-state input-output account for the US economy based on the BEA 1997 national benchmark IO table and detailed state level data from the 1997 economic Census and other ancillary data sets. The paper ends with conclusions and direction for future research. Appendix A contains a brief discussion of constrained matrix balancing literature. Appendix B lists the GAMS code of the model and data processing program.

\section{A Mathematical Programming Model for Estimating Interregional Trade and Inter- industrial Transaction Flows ${ }^{1}$}

Consider a national economy consisting of $\mathrm{N}$ sectors that are distributed over $\mathrm{M}$ regions. The sectors use each other's products as inputs for its own production, which is in turn used up either in further production or by consumers. Each region exports some of its products to other regions and some to other nations. They also import products from other regions and nations to meet their intermediate and final demand. Assuming a predetermined location of production that defines the structure of the national economic system of regions, the shipments of goods and services are determined by imbalances between supply and demand inside the different regions. Denote $\mathrm{STX}_{\mathrm{ir}}, \mathrm{STY}_{\mathrm{ir}}, \mathrm{SVA}_{\mathrm{ir}}, \mathrm{SEX}_{\mathrm{ir}}$, and $\mathrm{SMX}_{\mathrm{ir}}$ as sector i's total output, final demand, valueadded, exports, and imports in region $\mathrm{r}$ respectively, and denote $\mathrm{TX}_{\mathrm{i}}, \mathrm{TY}_{\mathrm{i}}, \mathrm{VA}_{\mathrm{i}}, \mathrm{EX}_{\mathrm{i}}$, and $\mathrm{MX}_{\mathrm{i}}$ as their respective national counterparts. Also denote $\mathrm{SHIP}_{\text {isr }}$ as shipment of sector i's products from region $\mathrm{s}$ to region $\mathrm{r}, \mathrm{SIX}_{\mathrm{ijr}}$ and $\mathrm{IX}_{\mathrm{ij}}$ as regional and national intermediate transaction from 
sector $\mathrm{i}$ to sector $\mathrm{j}$ respectively. All variables are measured in annual values. In such a static national system of economic regions, the following accounting identities must hold at each given year for all $i \in \mathrm{N}$ and $\mathrm{s}, \mathrm{r} \in \mathrm{M}$.

$$
\begin{aligned}
& \sum_{j=1}^{n} S I X_{i j r}+S V A_{i r}=S T X_{i r} \\
& \sum_{j=1}^{n} S I X_{i j r}+S T Y_{i r}=\sum_{s=1}^{m} S H I P_{i s r}+S M X_{i r} \\
& \sum_{s=1}^{m} S H I P_{i r s}+S E X_{i r}=S T X_{i r} \\
& \sum_{r=1}^{m} S I X_{i j r}=I X_{i j} \\
& \sum_{r=1}^{m} S T X_{i r}=T X_{i} \\
& \sum_{r=1}^{m} S V A_{i r}=V A_{i} \\
& \sum_{r=1}^{m} S T Y_{i r}=T Y_{i} \\
& \sum_{r=1}^{m} S E X_{i r}=E X_{i} \\
& \sum_{r=1}^{m} S M X_{i r}=M X_{i}
\end{aligned}
$$

The economic meanings of each of the nine equations are straightforward: equation (1) defines the sum of sector i's intermediate and primary factor inputs equals the sector's total output in each region. Equation (2) states the sum of each region's intermediate and final demand

1 The modeling framework is also a special case of constrained matrix balancing problem from mathematical perspective. It is a core mathematical structure for diverse empirical applications. See 
must be met by shipments from all regions (including from its own) within the nation plus imports from other nations. Equation 3 defines a region can only ship to all regions within the nation and export to other nations what it produces ${ }^{2,}$ while equations (4) -(9) are simply the facts that sums of all the region's economic activities within a nation must equal to the national totals. Having those accounting identities in mind, the estimation problem can be formally stated as follows:

Given a $n \times m \times m$ non-negative array $S_{H I P^{0}}=\left\{\right.$ ship $\left.^{0}{ }_{\text {isr }}\right\}$ and a $n \times n \times m$ non-negative array $S I X^{0}=\left\{\right.$ six $\left._{i j r}^{0}\right\}$, determine a non-negative array SHIP $=\left\{\right.$ ship $\left._{\text {isr }}\right\}$ and a non-negative array SIX $=$ $\left\{\right.$ six $\left.x_{i j r}\right\}$ that is close to SHIP $P^{0}$ and $S I X^{0}$ such that equations (1) to (9) are satisfied, where $s \in \mathrm{M}$ denotes the shipping regions, $r \in \mathrm{M}$ denotes the receiving regions, and $i, j \in \mathrm{N}$ denotes the make and use sectors respectively.

In plain English, the estimation problem is to modify a given set of prior inter-regional and interindustrial transaction estimates to satisfy the above nine known accounting constraints. The mathematical programming model conducting the estimation uses an objective function that penalizes the deviations of the estimated array SHIP and SIX from the initial array SHIP $^{0}$ and SIX ${ }^{0}$. Two types of alternative functional forms could be used:

(i) Quadratic function:

$$
\text { Min } Z=\frac{1}{2}\left\{\sum_{i=1}^{n} \sum_{s=1}^{m} \sum_{r=1}^{m} \frac{\left(\operatorname{SHIP}_{i s r}-\operatorname{ship}_{i s r}^{0}\right)^{2}}{s w_{i s r}}+\sum_{i=1}^{n} \sum_{j=1}^{n} \sum_{r=1}^{m} \frac{\left(S I X_{i j r}-s i x_{i j r}^{0}\right)^{2}}{w i i j r}\right\}
$$

(ii) Entropy function:

$$
\operatorname{Min} Z=\sum_{i=1}^{n} \sum_{s=1}^{m} \sum_{r=1}^{m} \frac{S H I P_{i s r}}{S w_{i s r}} \bullet L N\left(S H I P_{i r s} / s_{\text {hip }} i_{i r s}\right)+\sum_{i=1}^{n} \sum_{j=1}^{n} \sum_{r=1}^{m} \frac{S I X_{i s r}}{w i_{i s r}} \bullet L N\left(S I X_{i j r} / s i x_{i j r}^{0}\right)
$$

There are desirable theoretical properties of the above estimation framework that are well documented in the literature. Firstly, it is a separable nonlinear programming problem subject to appendix A for details. 
linear constraints. The entropy function is motivated from information theory and is the objective function underlying the well-known RAS procedure with row and column totals known with certainty (Senesen and Bates, 1988). It measures the information surprise contained in SHIP and SIX given the initial estimates $\operatorname{ship}^{0}$ and $\operatorname{six}^{0}$. The quadratic penalty function is motivated by statistical arguments. There are different statistical interpretations underlying the model by choices of different reliability weights $\mathrm{sw}_{\mathrm{isr}}$ and $\mathrm{wi}_{\mathrm{ij} \mathrm{j}}$. When the weights are all equal to one, solution of this model gives a constrained least square estimator. When the initial estimates are taken as the weights, solution of the model gives a weighted constrained least square estimator, which is identical to the Friedlander-solution, and a good approximation of the RAS solution. When those weights are proportional to the variances of the initial estimates and the initial estimates are statistically independent (the variance and covariance matrix of ship ${ }^{0}$ and $\operatorname{six}^{0}$ are diagonal), the solution of the model yields best linear unbiased estimates of the true unknown matrix (Byron, 1978), which is identical to the Generalized Least Squares estimator if the weights equal to the variance of initial estimates (Stone, 1984, Ploeg, 1984). Furthermore, as noted by Stone et al. (1942) and proven by Weale (1985), in cases where the error distributions of the initial estimates are normal, the solution also satisfies the maximum likelihood criteria. The corresponding likelihood function can be written as:

$$
L=\prod_{i=1}^{m} \prod_{j=1}^{n}\left(2 \pi w S_{i s r}\right)^{-\frac{n \bullet m \bullet m}{2}}\left(2 \pi w i_{i j r}\right)^{\frac{n \bullet m \bullet m}{2}} \bullet \exp ^{-\left\{\frac{\left(S H I P s r-s h i p_{i s r}^{0}\right)^{2}}{2 w S i s r}+\frac{\left(S I X j i r-s i x_{i j r}^{0}\right)^{2}}{2 w i j r}\right\}}
$$

2 Put another way, SHIP $_{\text {isr }}$ describes the process of transforming sector output $i$ of region $s$ into either an input of any sector $\mathrm{j}$ or the property of any final user in region $\mathrm{r}$. 
Secondly, the quadratic and entropy objective functions are equivalent in the neighborhood of initial estimates, under a properly selected weighing scheme. By taking second order Taylor expansion of the likelihood function (12) at point ( $\left.\operatorname{ship}_{i s r}, \operatorname{six}_{i j r}\right)$ we have

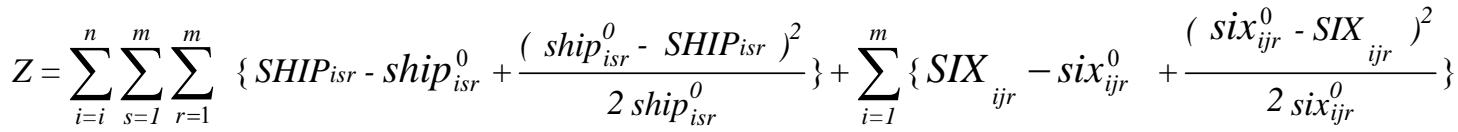

$$
\begin{aligned}
& =\frac{1}{2}\left\{\sum_{j=1}^{n} \sum_{s=1}^{m} \sum_{r=1}^{m} \frac{\left(\operatorname{SHIP}_{i s r}-\operatorname{ship}_{i s r}^{0}\right)^{2}}{\operatorname{ship}_{i s r}^{0}}+\sum_{i=1}^{n} \sum_{j=1}^{n} \sum_{r=1}^{m} \frac{\left(\operatorname{SIX}_{i j r}-\operatorname{six}_{i j r}^{0}\right)^{2}}{\operatorname{six}_{i j r}^{0}}\right\}+R
\end{aligned}
$$

This is the quadratic function (10) plus a remainder term R. As long as the posterior estimates and the prior estimates are close and the prior estimates are used as reliability weights ${ }^{3}$, the term $\mathrm{R}$ will be very small and the two objective functions thus can be regarded as approximating one another.

Thirdly, as proved by Harrigan (1990), in all but the trivial case, posterior estimates derived from entropy or quadratic loss minimand will always better approximate the unknown, true values than do the associated initial estimates. In this framework, information gain is interpreted as the imposition of additional valid constraints or the narrowing of bounds on existing constraints as long as the true but unknown values belong to the feasible solution set. This is because adding valid constraints or further restricting the feasible set through the narrowing of interval constraints cannot move the posterior estimates away from the true values, unless the additional constraints are non-binding (have no information value). Although the

3 The quadratic functional form has a numerical advantage in implementing the model. It is easier to solve than the entropy function in very large models because they can be solved by software specifically designed for quadratic programming. 
posterior estimates may not always be regarded as providing a "reasonable" approximation to the true value ${ }^{4}$, the resulting constrained estimates are always better than the initial estimates in the sense the former is closer to the true value than the later, so long as the imposed constraints are true. In other words, the optimization process has the effect of reducing, or at least not increasing, the variance of the estimates. This property is simple to show by using matrix notation. Define W as the variance matrix of initial estimates ship ${ }^{0}, \mathrm{~A}$ as the coefficient matrix of all linear constraints. The least squares solution (equivalent to the quadratic minimand as noted above) to the problem of adjusting ship ${ }^{0}$ to SHIP, which satisfies the linear constraint, A•SHIP $=$ 0 can be written as:

$$
\mathrm{SHIP}=\left(\mathrm{I}-\mathrm{WA}^{\mathrm{T}}\left(\mathrm{AWA}^{\mathrm{T}}\right)^{-1} \mathrm{~A}\right) \mathrm{SHIP}^{0}
$$

Thus

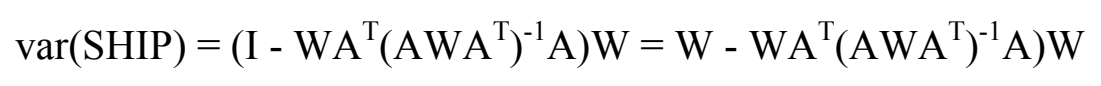

since $\left.\mathrm{WA}^{\mathrm{T}}\left(\mathrm{AWA}^{\mathrm{T}}\right)^{-1} \mathrm{~A}\right) \mathrm{W}$ is a positive semi-definite matrix, the variance of posterior estimates will always be less, or at least not greater than the variance of the initial estimates as long as A $\bullet$ SHIP ${ }^{\text {true }}=0$ holds. This is the fundamental reason why such an estimating framework will provide better posterior estimates. Imposing accounting relationship's (1)-(9) will definitely improve, or at least not worsen the initial estimates, since we are sure from economics those constraints are identities and must be true for any national system of economic regions.

Finally, the choice of weights in the objective function has very important impacts on the estimation results. For instance, using the initial estimates as weights has the nice property that each entry of the array is adjusted in proportion to its magnitude in order to satisfy the

\footnotetext{
${ }^{4}$ The minimand objective function reflects the principle that the 'distance' between the posterior and prior estimates should be minimized. While what we would like is to minimize is the 'distance' between the posterior estimates and the unknown true values. This 'distance' can not be measured, but a good estimation procedure should have a desirable influence on it.
} 
accounting identities, and the variables can not change sign and that large variables are adjusted more than small variables. However, the adjustment relates directly to the size of the initial estimates ship ${ }_{\text {isr }}^{0}$ and $\operatorname{six}^{0}{ }_{\mathrm{ijr}}$, and does not force the unreliable prior to absorb the bulk of the required adjustment. Furthermore, only under the assumptions: (1) the initial estimates for different elements in the array are statistically independent, and (2) each error variance is proportional to the corresponding initial estimates, this commonly used weighing scheme (underlying RAS) can obtain best unbiased estimates, while those assumptions may not hold in many cases. Fortunately, the model is not restricted to use a diagonal-weighing matrix such as the priors only. When a variance-covariance matrix of the initial estimates is available, it can be incorporate into the model by modifying the objective function as follows:

$$
\operatorname{Min} Z=\left(S H I P-S H I P^{0}\right) W S^{-1}\left(S H I P-S H I P^{0}\right)+\left(S I X-S I X^{0}\right)^{T} W I^{-1}\left(S I X-S I X^{0}\right)
$$

The efficiency of the resulting posterior estimator will be further improved if the error structure of the priors is available, because such a weighting scheme makes the adjustment independent of the size of the priors. The larger the variance, the smaller its contribution to the objective function, and hence the less punishment for ship $\mathrm{isr}_{\mathrm{in}}$ and $\mathrm{six}_{\mathrm{ijr}}$ to move away from their priors (only the relative, not the absolute size of the variance affects the solution). A small variance of the priors indicates they are very reliable data and thus should not change by much, whilst a large variance of the priors indicates unreliable data and will be adjusted considerably in the solution process. Therefore, this weighing scheme gives the best-unbiased estimates of the true, unknown inter-regional and inter-industrial transaction value under the assumption that initial estimates for different elements in the array are statistically independent. Although there is not much difficulty to solve such a nonlinear programming problem like this today, the major problem is lack of data to estimate the variance-covariance matrix associate with the priors. 
Stone (1982) proposed to estimate the variance of $\operatorname{six}^{0}{ }_{\mathrm{ijr}}$ as $\operatorname{var}\left(\operatorname{six}_{\mathrm{ijr}}^{0}\right)=\left(\theta_{\mathrm{ijr}} \operatorname{six}_{\mathrm{ijr}}\right)^{2}$, where $\theta_{\mathrm{ij}}$ is a subjectively determined reliability rating, expressing the percentage ratio of the standard error to $\operatorname{six}_{\mathrm{ijr}}^{0}$. Weale (1989) had used time series information on accounting discrepancies to infer data reliability. The similar methods can be used to derive variances associated with those initial estimates in our model.

Despite the difficulties in obtaining data for the best weighting scheme, advantages of such a model in estimating inter-regional shipments and inter-industrial transactions are still obvious from an empirical perspective. Firstly, it is very flexible regarding the required know information. For example, it allows for the possibility that the state total of output, value-added, exports, imports and final demands are not known with certainty. In the real world, these regional totals typically have substantial gaps and inconstancies with the national total. Incorporating associated terms similar to $\mathrm{SHIP}^{0}$ and $\mathrm{SIX}^{0}$ in the objective function to penalize solution deviations from the initial estimates from statistical sources allows the estimation of those regional totals, together with entries in the inter-regional shipping and inter-industrial transaction array. With the use of upper and lower bounds, this fact can also be modeled by specifying ranges rather than precise values for the linear constraints (1) - (3). In addition, the estimation of SHIP or SIX will be a special case of the framework when only one set of additional data is available.

Secondly, it permits a wider variety and volume of information to be brought to bear on the estimation process than what is possible with scaling methods. For example, the ability of introducing upper and/or lower bounds on those regional totals is one of the flexibilities not offered by commonly used scaling procedures such as RAS. The gradient of the entropy function tends to infinity as ship $\mathrm{isr}_{\text {and }}$ six $\mathrm{x}_{\mathrm{ijr}} \rightarrow 0$, and hence restricts the value of the posterior estimates to 
nonnegative. This is a desirable property of estimating inter-regional trade data. Such nonnegativity requirements can be enforced in the case of quadratic penalties through the use of lower bounds on the values of ship $\mathrm{isr}_{\mathrm{isr}}$ and $\mathrm{six}_{\mathrm{ij} \text {. }}$.

Thirdly, the weights in the objective function reflect the relative reliability of a given set of priors. The interpretation of the reliability weights is straightforward. Entries with higher reliability should be changed less than entries with a lower reliability. The choice of those weights is also very flexible. They will use the best available information to insure that reliable data in the prior estimates are not being modified by the optimization model as much as unreliable data. In practice, such reliability weights can be put into a second array that has the same dimension and structure as the priors. The inverted variance-covariance matrix of the priors can be interpreted as the best index of the reliability for the initial data by statistics.

Finally, solution of this estimation problem exactly provide the data needed to construct a so called multi-regional input-output (MRIO) model in the IO literature (Miller and Blair, 1985, Isard, et al. 1998), which was pioneered by professor Polenske and her associates at MIT in the 1970's (Polenske, 1980), and is still widely used in regional economic impact analysis today.

The above model could be easily extended to further allocate SIX and SHIP to distinguish intermediate and final delivery of good and services within a national system of economic regions. The extended model will be similar in many aspects with the interregional accounting framework proposed by David F. Batten (1982) two decades ago. However, as we will show later in this paper, it becomes more operational and provides much better empirical estimation results on interregional shipments because of the explicit incorporation of interregional trade flow information into both the initial estimates and the accounting framework. 
To demonstrate, denote $\mathrm{SX}_{\mathrm{ijsr}}$ as intermediate inputs delivered from sector $\mathrm{i}$ in region $\mathrm{s}$ to sector $\mathrm{j}$ in region $\mathrm{r}$ within a nation, and $\mathrm{SY}_{\mathrm{ihsr}}$ as final goods and services delivered from sector $\mathrm{i}$ in region $\mathrm{s}$ to type $\mathrm{h}$ final demand in region r. Further, denote $\mathrm{SIM}_{\mathrm{ijr}}$ and $\mathrm{SIY}_{\mathrm{ihr}}$ as imported (from other nations) intermediate and final goods and services delivered to sector $\mathrm{j}$ or final demand type $\mathrm{h}$ in region $\mathrm{r}$ respectively. Other notation regarding state total output, intermediate inputs, value-added, exports and imports are the same with the aggregated model. Then the accounting framework for the national system of economic regions can be defined as follows:

$$
\begin{aligned}
& \sum_{j=1}^{n} \sum_{s=1}^{m} S X_{j i s r} \sum_{j=1}^{n} S I M_{j i r}+S V A_{i r}=S T X_{i r} \\
& \sum_{j=1}^{n} \sum_{s=1}^{m} S X_{i j r s}+\sum_{j=1}^{n} S I M_{i j r}+\sum_{h=1}^{h} \sum_{s=1}^{m} S Y_{i h r s}+\sum_{j=1}^{n} S I Y_{i h r}+S E X_{i r}=S T X_{i r}+S M X_{i r} \\
& \sum_{h=1}^{h} \sum_{s=1}^{m} S Y_{i h s r}+\sum_{h=1}^{h} S I Y_{i h r}=S T Y_{i r} \\
& \sum_{j=1}^{n} S X_{i j s r}+\sum_{h=1}^{h} S Y_{i h s r}=S H I P_{i s r} \\
& \sum_{s=1}^{m} S X_{i j s r}=S I X_{i j r} \\
& \sum_{j=1}^{n} S I M_{i j r}+S I Y_{i r}=S M X_{i r}
\end{aligned}
$$

Adding a quadratic penalty objective function, we have an extended model to estimate a detailed interregional input-output account based on the results from the earlier model ${ }^{5}$.

5 By incorporated the 6 accounting identities that the sum of all regions in the nation should equals their national totals defined in equation (4-9), the model could be solved independently without use of the earlier model, however, the dimension of the model will be much higher and data requirements will be much larger than the earlier model. 


$$
\begin{aligned}
\operatorname{Min} Z & =\frac{1}{2}\left\{\sum_{s=1}^{m} \sum_{r=1}^{m} \sum_{i=1}^{n} \sum_{j=1}^{n} \frac{\left(S X_{i j s r}-S X_{i j s r}^{0}\right)^{2}}{w X_{i j s r}}+\sum_{n=1}^{m} \sum_{i=1}^{n} \sum_{h=1}^{h} \sum_{j}^{n} \frac{\left(S Y_{i h s r}-s y_{i h s r}^{0}\right)^{2}}{w y_{i h j r}}\right. \\
& \left.+\sum_{r=1}^{m} \sum_{i=1}^{n} \sum_{j=1}^{n} \frac{\left(S I M_{i j r}-s i m_{i j r}^{0}\right)^{2}}{w i x_{i j r}}+\sum_{n=1}^{m} \sum_{i=1}^{n} \sum_{h=1}^{h} \frac{\left(S I Y_{i h r}-s i y_{i h r}^{0}\right)^{2}}{w i y_{i h r}}\right\}
\end{aligned}
$$

This model has the theoretical and empirical properties similar to the earlier model, but with much higher details. The solution to 23 , subject to constraints $17-22$, provides a complete set of data for a so called inter-regional input-output (IRIO) model with imports endogenous in the IO literature (Miller and Blair, 1985, Isard, et al. 1998).

\section{Empirical Test of the Model and Evaluation Measures}

\subsection{The testing data set}

How does the model specified above perform when applied to data from the real world? In order to evaluate the models' performance, a benchmark data set from the real world is needed. Because good interregional trade data is quite rare and very difficulty to obtain in any countries of the world, a natural place to find such data sets is existing global production and trade databases such as the GTAP (Global Trade Analysis Project) database. For instance, version 4 GTAP database contains detailed bilateral trade, transportation, and individual country's input-output data covering 45 countries and 50 sectors (McDougall, Elbehri, and Truong, 1998). For our particular purpose, version 4 GTAP database was first aggregated into a 4-region, 10-sector data set. Then three of the four regions (the United States, European Union and Japan) were further aggregated into a single open economy which engages in both interregional trade among its 3 internal regions and international trade with rest of the world. 
We will use this partitioned data set as the benchmark multi-regional input-output account for a hypothetical national economy, and attempt to use our model to replicate the underlying intercontinental trade flows among Japan, EU and the United Sates as well as the individual country's input-output account.

\subsection{Experiment design}

In the first experiment, we do this without use of the region-specific input-output coefficients as the situation encountered in the real world, where only the national IO table is available to economists (it is the three region's weighted average in our experiment). Using initial estimates of interregional commodity flow that are distorted from the 'true' interregional trade data in the GTAP data by a normal distributed random error term with zero mean and the size of standard deviation as large as 5 times the "true" trade data. The solution from the model is compared with the benchmark data set for both the inter-regional shipment and inter-sector transaction flows.

In the second experiment, we use the region-specific input-output coefficients as constant in the model. We re-estimate the interregional shipment data as the first experiment, and compare the model solution with the benchmark data set for the inter-regional trade data only.

In the third experiment, we assume the interregional shipment pattern is known with certainty, we use the three region's weighted average IO coefficients as priors (which is defined as $\mathrm{IX}_{\mathrm{ij}} /\left(\mathrm{TX}_{\mathrm{ij}}-\mathrm{VA}_{\mathrm{i}}\right) *\left(\mathrm{STX}_{\mathrm{ir}}-\mathrm{SVA}_{\mathrm{ir}}\right)$ to make full use of the known information) to estimate the region-specific input-output account.

In the fourth experiment, David F. Batten's model was used to estimate the interregional shipment and individual region IO flows. In the fifth to the seventh experiments, experiments 1-3 were repeated by using the extended model. Solution from both models is compared with the 
"true" interregional trade and inter-sector IO flow data in the aggregated GTAP data set. The assumptions, initial estimate and expected model solution are summarized in table 1.

\section{Table 1 Experiment Design}

\begin{tabular}{|c|c|c|c|}
\hline $\begin{array}{l}\text { Experiment } \\
\text { number }\end{array}$ & $\begin{array}{c}\text { Data Know with } \\
\text { Certainty } \\
{ }^{1}\end{array}$ & Initial Estimates & $\begin{array}{c}\text { What is estimated } \\
\text { by the model }\end{array}$ \\
\hline 1 & None & $\begin{array}{l}\text { Ship }_{i s r}^{r} \text { is distorted from the "true" data ship }{ }_{i s r}^{0} \\
S_{i x}^{r}{ }_{i j r}=I X_{i j} /\left(T X_{i j}-V A_{i}\right) \times\left(S T X_{i r}-S V A_{i r}\right)\end{array}$ & SHIP and SIX \\
\hline 2 & $\mathrm{SIX}=\mathrm{SIX}^{0}$ & Ship $_{i s r}^{r}$ is distorted from the "true" data ship ${ }_{i s r}$ & SHIP only \\
\hline 3 & $\mathrm{SHIP}=\mathrm{SHIP}^{0}$ & $S i x_{i j r}^{r}=I X_{i j} /\left(T X_{i j}-V A_{i}\right) \times\left(S T X_{i r}-S V A_{i r}\right)$ & SIX only \\
\hline 4 & None & $\begin{array}{l}s X_{i j s r}^{0}=\left[\left(S T X_{i s}+S M X_{i s}-S E X_{i s}\right) /\left(T X_{I}+M X_{i}-\right.\right. \\
\left.\left.E X_{i}\right)\right] \times\left[\left(S T X_{j r}-S V A_{j r}\right) /\left(T X_{j}-V A_{j}\right)\right]^{*} I X_{i j} \\
s y^{0}=\left[\left(S T X_{i s}+S M X_{i s}-S E X_{i s}\right) /\left(T X_{i}+M X_{i}-\right.\right. \\
\left.\left.E X_{i}\right)\right] \times S T Y_{i r} \quad \text { Eqs. (16) and (17) in Batten }(1982)\end{array}$ & SHIP and SIX \\
\hline 5 & None & $\begin{array}{l}s x_{i j s r}^{0}=\left[\left(\operatorname{Six}_{i j r}^{r} /\left(\sum_{j} \operatorname{Six}_{i j r}^{r}+S T Y_{i r}\right)\right] \times \operatorname{Ship}_{i s r}^{r}\right. \\
s y_{i s r}^{0}=\left[\left(\operatorname{STY}_{i r} /\left(\sum_{j} S i x_{i j r}^{r}+S T Y_{i r}\right)\right] \times \operatorname{Ship}_{i s r}^{r}\right.\end{array}$ & SHIP and SIX \\
\hline 6 & $\mathrm{SIX}=\mathrm{SIX}^{0}$ & $\begin{array}{l}s x_{i j s r}^{0}=\left[\left(\operatorname{Six}_{i j r}^{0} /\left(\sum_{j} \operatorname{Six}_{i j r}^{0}+S T Y_{i r}\right)\right] \times \operatorname{Ship}_{i s r}^{r}\right. \\
s y_{i s r}^{0}=\left[\left(\operatorname{STY}_{i r} /\left(\sum_{j} \operatorname{Six}_{i j r}^{0}+S T Y_{i r}\right)\right] \times \operatorname{Ship}_{i s r}^{r}\right.\end{array}$ & SHIP only \\
\hline 7 & $\mathrm{SHIP}=\mathrm{SHIP}^{0}$ & $\begin{array}{l}s x_{i j s r}^{0}=\left[\left(\operatorname{Six}_{i j r}^{r} /\left(\sum_{j} S i x_{i j r}^{r}+S T Y_{i r}\right)\right] \times \operatorname{Ship}_{i s r}^{0}\right. \\
s y_{i s r}^{0}=\left[\left(S T Y_{i r} /\left(\sum_{j} S i x_{i j r}^{r}+S T Y_{i r}\right)\right] \times \text { Ship }_{i s r}^{0}\right.\end{array}$ & SIX only \\
\hline
\end{tabular}

Note:

1. In all experiments, national totals: $\mathrm{IX}_{\mathrm{ij}}, \mathrm{TX}_{\mathrm{i}}, \mathrm{TY}_{\mathrm{i}}, \mathrm{VA}_{\mathrm{i}}, \mathrm{EX}_{\mathrm{i}}$, and $\mathrm{MX}_{\mathrm{i}}$ are known with certainty, i.e. they enter the model as constant. It is not necessary for the state totals: STX $\mathrm{ir}, \mathrm{STY}_{\mathrm{ir}}, \mathrm{SVA}_{\mathrm{ir}}, \mathrm{SEX}_{\mathrm{ir}}$, and $\mathrm{SMX}_{\mathrm{ir}}$ to be know as certainty in the model, however, in all experiment reported in this paper, they enter the model as constant. The relative importance of the different items of regional totals will be explored in the next set of experiments.

2. In experiment 5-7, we did not distinguish different final demand types when the extended model is used. 


\subsection{Measures to evaluate test results}

Each experiment produces a different set of estimates, and it is desirable to know how much each set of estimates differs from the true, known data. However, it is difficult to use a single measure to compare the estimated results. Since there are so many dimensions in the model solution sets, a particular set of estimates may score well on one region or commodity but badly on others. It is meaningful to use several measures to gain more insight on the model performance in different experiments. Generally speaking, it is the large proportionate errors but not the large absolute error that matter, therefore, the "Mean absolute Percentage Error" with respect to the true data will be calculated for different commodity and regional aggregations. The following eight index measures will be used in evaluating the model solution:

(1) Total Mean absolute percentage error (MAPE) of shipment estimates:

$$
M_{A P E^{s h i p}}=\frac{100 \bullet \sum_{i=1}^{n} \sum_{s=1}^{m} \sum_{r=1}^{m} \mid \text { SHIP isr }- \text { ship }_{\text {isr }}^{0} \mid}{\sum_{i=1}^{n} \sum_{s=1}^{m} \sum_{r=1}^{m} \operatorname{ship}_{i s r}^{0}}
$$

(2) Total Mean absolute percentage error (MAPE) of IO transaction estimates:

$$
\operatorname{MAPE}^{S i x}=\frac{100 \bullet \sum_{i=1}^{n} \sum_{j=1}^{n} \sum_{r=1}^{m}\left|S I X_{i j r}-\operatorname{six} X_{i j r}^{0}\right|}{\sum_{i=1}^{n} \sum_{j=1}^{n} \sum_{r=1}^{m} \operatorname{six}_{i j r}^{0}}
$$

(3) Mean absolute percentage error of shipment estimates by commodities:

$$
\operatorname{MAPE}_{i}{ }^{\text {ship }}=\frac{100 \bullet \sum_{s=1}^{m} \sum_{r=1}^{m} \mid \text { SHIP }_{\text {isr }}-\text { ship }_{i s r}^{0} \mid}{\sum_{s=1}^{m} \sum_{r=1}^{m} \operatorname{ship}_{i s r}^{0}}
$$


(4) Mean absolute percentage error of shipment estimates by shipping regions

$$
\text { MAPE }_{s}^{\text {ship }}=\frac{100 \cdot \sum_{i=1}^{n} \sum_{r=1}^{m} \mid \text { SHIP } i s r-\text { ship }_{i s r}^{0} \mid}{\sum_{i=1}^{n} \sum_{r=1}^{m} \operatorname{ship}_{i s r}^{0}}
$$

(5) Mean absolute percentage error of shipment estimates by receiving regions

$$
\text { MAPE }_{r}^{\text {ship }}=\frac{100 \bullet \sum_{i=1}^{n} \sum_{s=1}^{m} \mid \text { SHIP } i s r-\text { ship }_{i s r}^{0} \mid}{\sum_{i=1}^{n} \sum_{s=1}^{m} \operatorname{ship}_{i s r}^{0}}
$$

(6) Mean absolute percentage error of IO transaction estimates by inputs

$$
\operatorname{MAPE}_{j}{ }^{s i x}=\frac{100 \bullet \sum_{j=1}^{n} \sum_{r=1}^{m}\left|S^{\prime} X_{j i r}-\operatorname{six}_{j i r}^{0}\right|}{\sum_{j=1}^{n} \sum_{r=1}^{m} \operatorname{six}_{j i r}^{0}}
$$

(7) Mean absolute percentage error of IO transaction estimates by use

$$
\operatorname{MAPE}_{i}{ }^{s i x}=\frac{100 \bullet \sum_{j=1}^{n} \sum_{r=1}^{m}\left|S_{i j} X_{i j r}-\operatorname{six}_{i j r}^{0}\right|}{\sum_{j=1}^{n} \sum_{r=1}^{m} \operatorname{six} x_{i j r}^{0}}
$$

(8) Mean absolute percentage error of IO transaction estimates by region

$$
\operatorname{MAPE}_{r} \text { six }=\frac{100 \cdot \sum_{i=1}^{n} \sum_{j=1}^{n}\left|S I X_{i j r}-\operatorname{six}_{i j r}^{0}\right|}{\sum_{i=1}^{n} \sum_{j=1}^{n} \operatorname{six} x_{i j r}^{0}}
$$

The model and all test experiments are implemented in GAMS and the complete GAMS program is listed in Appendix B. 


\subsection{Testing results}

Table 2 summarizes all the eight measurement indexes from the seven testing experiments listed in Table 1 . The accuracy of the estimates is judged by their closeness to the true interregional trade and individual region's input-output flows aggregated from the GTAP database.

\section{(Insert Table 2 here)}

Generally speaking, the model has remarkable capacity to rediscover the true interregional trade flows from the highly distorted data. The estimated shipment data are very close to the true data by the eight types of measurement in all testing experiments except the Batten model. Most of the mean absolute percentage errors are about 4-7 percent of the true data value, which implies the model has great potential in the application of estimating interregional trade flows. In contrast, recovering the individual region's input-output flows from national average values only obtained very limited success, indicating national detailed IO coefficients may be the best place to start in building regional IO account if there is no additional prior information on regional technology or cost structure available.

Comparing estimates from different test experiments, there are several interesting observations. First, when there is no additional information that could be incorporated into the estimation framework, a more detailed model may not perform better than a simpler model (compare results from Exp-1 and Exp-5, the more sophisticated extended model actually bring less accurate estimates overall because of losing degrees of freedom). However, as results in Experiments 2-3 and 6-7 show, the estimation accuracy does improve by a more detailed model when more useful data become available. Second, the marginal accuracy gained from actual individual regional IO flows is significant in estimating interregional trade flow using the 
extended model, but quite small in the aggregate version. In contrast, the marginal value of accurate interregional shipment data is rather small in estimating individual regional IO coefficients under both versions of the model. Finally, Batten's model performed poorly in interregional shipment estimation, but obtained very similar estimates on individual regional IO flows as our model, providing further evidence that there may be no high dependency between individual regional IO coefficients and interregional trade flows. However, caution may be needed for a firm conclusion because the particular data set used to test the model in this paper may be part of the problem. Since the United States, EU and Japan are all large economies, their intermediate demands are largely meet by their own production. Therefore, the correlation between their individual inter-industrial flow and inter-regional shipments may be particular low. This may be responsible for the insensitivity of their IO flow estimates to changes in interregional shipment data. In most single country regional models, inter-regional trade flows are likely to provide a substantial share of intermediate and final demand needs within the region.

Because the extended model only provide better estimates of interregional shipments when individual regional IO data are available, the aggregate version of the model specified in this paper may be the best practitioner's tool in estimating interregional trade flows. It not only demands less statistical information, but also has a smaller model dimension, which will facilitate the implementation and computation process ${ }^{6}$.

6 The aggregate model only has $\mathrm{N}\left(\mathrm{NM}+\mathrm{M}^{2}+5 \mathrm{M}\right)$ variables and $\mathrm{N}(3 \mathrm{M}+\mathrm{N}+5)$ constraints, while the extended model has $\left(\mathrm{N}^{2} \mathrm{M}+\mathrm{NHM}\right)(\mathrm{M}+1)$ variables and $\mathrm{N}\left(\mathrm{M}^{2}+\mathrm{NM}+\mathrm{N}+5\right)$ constraints. This is a much larger model, having $\mathrm{NM}^{2}(\mathrm{~N}-1)+\mathrm{NM}(\mathrm{HM}-5)$ more variables and $\mathrm{MN}(\mathrm{M}+\mathrm{N}-3)$ additional constraints. 
Table 2 Mean Absolute Percentage Error from the True Data \%

\begin{tabular}{|c|c|c|c|c|c|c|c|c|c|c|c|c|}
\hline \multirow{2}{*}{\begin{tabular}{|l|} 
Experiment \# \\
Indexes \\
\end{tabular}} & \multicolumn{2}{|c|}{ Distorted priors } & \multicolumn{2}{|c|}{ Exp-1 } & \multirow{2}{*}{$\begin{array}{l}\text { Exp-2 } \\
\text { Ship }_{\text {isr }} \\
\end{array}$} & \multirow{2}{*}{$\begin{array}{c}\text { Exp-3 } \\
\text { six }_{\mathrm{ijr}} \\
\end{array}$} & \multicolumn{2}{|c|}{ Exp-4 Batten model } & \multicolumn{2}{|c|}{ Exp-5 } & \multirow{2}{*}{$\begin{array}{l}\text { Exp-6 } \\
\text { Ship }_{\text {isr }} \\
\end{array}$} & \multirow{2}{*}{$\begin{array}{c}\text { Exp-7 } \\
\text { six }_{\text {ijr }} \\
\end{array}$} \\
\hline & Ship $_{\text {isr }}$ & Ave. IO & Ship $_{\text {isr }}$ & $\operatorname{six}_{\mathrm{ijr}}$ & & & Ship $_{\text {isr }}$ & $\operatorname{six}_{\mathrm{ijr}}$ & Ship $_{\text {isr }}$ & $\operatorname{six}_{\mathrm{ijr}}$ & & \\
\hline Total MAPE & 399.75 & 21.79 & 6.38 & 20.58 & 5.69 & 19.30 & 126.13 & 18.54 & 7.34 & 22.04 & 2.05 & 18.17 \\
\hline \multicolumn{13}{|l|}{ Receiving region MAPE } \\
\hline United States & 265.83 & 19.63 & 9.31 & 21.05 & 8.68 & 17.29 & 129.88 & 16.49 & 10.75 & 26.15 & 3.90 & 14.94 \\
\hline European Union & 447.06 & 16.87 & 4.64 & 15.38 & 3.61 & 15.44 & 111.73 & 16.51 & 5.28 & 15.43 & 0.74 & 15.62 \\
\hline Japan & 494.73 & 33.26 & 5.53 & 29.38 & 5.34 & 28.68 & 145.59 & 24.68 & 6.39 & 28.95 & 1.86 & 26.68 \\
\hline Sector MAPE I & & Inputs & & & & & & & & & & \\
\hline Primary agriculture & 304.53 & 29.86 & 6.19 & 30.58 & 5.19 & 30.32 & 125.51 & 34.92 & 8.42 & 33.34 & 1.67 & 32.11 \\
\hline Processed agriculture & 319.40 & 21.65 & 9.20 & 17.12 & 10.67 & 15.80 & 129.42 & 13.06 & 9.86 & 18.21 & 2.97 & 13.35 \\
\hline Resource based sectors & 392.24 & 18.26 & 8.78 & 15.36 & 5.52 & 14.90 & 135.00 & 13.28 & 10.16 & 15.12 & 2.15 & 13.03 \\
\hline Non-durable goods & 312.28 & 12.50 & 4.47 & 10.40 & 3.85 & 11.29 & 127.87 & 11.44 & 5.39 & 11.08 & 3.36 & 8.76 \\
\hline Durable goods & 413.91 & 16.42 & 4.54 & 15.50 & 4.36 & 14.69 & 121.60 & 14.06 & 4.89 & 15.83 & 3.38 & 11.46 \\
\hline Utility & 774.76 & 33.00 & 6.54 & 30.74 & 1.40 & 28.87 & 121.86 & 24.73 & 7.24 & 31.80 & 0.95 & 26.56 \\
\hline Construction & 484.64 & 34.41 & 1.71 & 27.66 & 2.61 & 28.48 & 133.12 & 22.53 & 6.15 & 28.18 & 0.01 & 27.41 \\
\hline Trade and Transport & 406.12 & 30.23 & 12.70 & 30.95 & 12.68 & 27.23 & 130.52 & 20.83 & 13.07 & 33.02 & 3.08 & 25.67 \\
\hline Private services & 245.15 & 13.71 & 5.38 & 16.60 & 5.07 & 14.38 & 126.71 & 20.30 & 6.46 & 20.28 & 1.17 & 18.85 \\
\hline Public services & 539.32 & 37.84 & 4.11 & 31.53 & 1.30 & 30.57 & 118.65 & 29.77 & 4.28 & 32.72 & 0.62 & 25.01 \\
\hline \multicolumn{13}{|l|}{ Shipping region MAPE } \\
\hline United States & 264.78 & & 9.83 & & 9.08 & & 130.65 & & 10.60 & & 2.90 & \\
\hline European Union & 445.56 & & 4.60 & & 3.65 & & 111.83 & & 5.69 & & 1.57 & \\
\hline Japan & 495.24 & & 4.96 & & 4.80 & & 144.28 & & 5.93 & & 1.75 & \\
\hline & & & & & & & & & & & & \\
\hline Sector MAPE II & & Use & & & & & & & & & & \\
\hline Primary agriculture & & 32.55 & & 18.54 & & 19.54 & & 12.03 & & 17.38 & & 17.62 \\
\hline Processed agriculture & & 17.39 & & 24.60 & & 19.03 & & 18.90 & & 28.64 & & 18.47 \\
\hline \multicolumn{2}{|l|}{ Resource based sectors } & 23.05 & & 22.63 & & 21.23 & & 21.81 & & 23.24 & & 20.57 \\
\hline Non-durable goods & & 12.21 & & 11.13 & & 11.55 & & 12.32 & & 12.20 & & 10.39 \\
\hline Durable goods & & 11.79 & & 11.88 & & 11.53 & & 12.40 & & 11.30 & & 9.65 \\
\hline Utility & & 40.51 & & 32.93 & & 33.87 & & 29.16 & & 30.23 & & 26.15 \\
\hline Construction & & 54.23 & & 49.58 & & 46.69 & & 46.29 & & 47.20 & & 40.67 \\
\hline Trade and Transport & & 19.81 & & 20.10 & & 18.19 & & 20.88 & & 28.91 & & 17.86 \\
\hline Private services & & 25.88 & & 24.24 & & 22.19 & & 16.68 & & 24.94 & & 23.48 \\
\hline Public services & & 37.50 & & 35.59 & & 34.11 & & 50.94 & & 35.51 & & 26.18 \\
\hline
\end{tabular}




\section{Empirical Issues when the Model is applied to the US Economy}

To implement the model in the context of the United States, the first task is assembling data from different sources. This data will be used to specify the national input-output account, sector totals of output, value-added, exports, imports and final demand at the state level as well as initial information of inter/intra-state commodity shipments. Much of this information is available directly from official statistical sources.

The Detailed Benchmark Input-Output Account of the United States ${ }^{7}$ is estimated every five years, with the most recent benchmark having been published in December of 2002 by the Bureau of Economic Analysis (BEA), based on calendar year 1997 economic statistics. As is true for the majority of nations who maintain official national economic accounting systems, the U.S. system of official economic statistics does not include an interregional, inter-industry accounting system.

The benchmark account coincides with the calendar year economic statistics of the Economic Census and Census of Governments (U.S. Dept. of Census), Census of Agriculture (U.S. Dept. of Agriculture), and other ancillary U.S. regional economic accounts. State level statistics on gross output, value added and/or total wage-bill are, for the most part, routinely extracted from these sources. Other relevant statistics include annual industry gross state product accounts (BEA), 'origin of movement' State export statistics and import statistics by port of entry into the U.S. (Census) ${ }^{8}$. Finally, depending on the emphasis of the modeler's application,

7 This 'detailed' account characterizes all U.S. domestic inter-industry activities for calendar year 1997, as summarized into 491 industry aggregates, 483 commodity aggregates, and U.S. GDP by commodity, broken out into personal consumption, gross private investment, net exports, inventory change, and government investment and consumption.

8 Equations (2) and (3) can be modified to be consistent with those officially published export and import statistics. 
other Federal and State Government statistics, trade association data, and proprietary data have useful information that will complement the primary official data sources.

State final demand statistics are the only data items that are not as routinely extracted from primary data sources. Important indirect information that can be used to estimate State consumer expenditures include the Bureau of Labor Statistics (BLS), Consumer Expenditure Survey (CES), the decennial Census of Population, and Internal Revenue Service (IRS) statistics on income. For example, using BLS regional CES tables, one can allocate U.S. expenditure data out to one of four U.S. regions. Next, using CES expenditure statistics by household income, and by other socioeconomic categories, one can use Census of Population State statistics to further allocate regional expenditure estimates out to States.

For gross private investment, BEA produces detailed wealth account statistics that include annual gross private investment by major industry groups. The Internal Revenue Service publishes State investment and depreciation statistics that allow one to infer the level and type of investments that business' and households are making in each state. Combining these data with the national private investment statistics by detailed commodity groups, one can develop regional estimates of gross private state investment. Federal and State procurement data are available from two comprehensive sources, the General Services Administration and the U.S. Census of Governments. Perhaps the most elusive information is that on State inventory change. State level information does exist for some of the 483 Commodity aggregates, and this data can supplement estimates that assume, at the detailed commodity level, that inventory change is a constant percentage of both national and State final demand.

The confidence of the developer in their estimates may depend on their abilities to obtain relevant data not typically available. This data can be used to fill data gaps created by 
deficiencies of the conventional data sources. If that confidence exists, estimates of State level data on output, value added, imports, exports, and total final demand, by commodity, can be used as the 'true' identities in solving the national system of regional input-output accounts. To the extent that a subset of this data is considered unreliable, employing methods of attaching reliability weights (Stone, 1982,1988) to these suspect data points can facilitate the more general specification of the models presented in the previous section.

Whichever approach one takes, the most challenging empirical obstacle to solving an U.S. balanced IRIO from the model is the development of regional technical input-output coefficient priors, and inter/intra-regional shipment data priors. Two very useful 'rules of thumb' can be applied to this problem and when applied together, can reinforce each other.

One often-applied 'rule' is known as the product mix approach (Miller \& Blair, 1985, p. 70). This approach requires that, in lieu of other information on the regional technical coefficients, estimates of the product mix for the detailed industries that map into a regional commodity aggregate should be used. With this information, a weighted average of the national input-output coefficients of these products, where the weights are the share of regional aggregate commodity gross output that each detailed industry represents, produces a unique regional coefficient for each commodity aggregate represented in the regional system.

Another useful 'rule' pertains to the use of aggregate transportation data. This rule states that in lieu of detailed transportation statistics on inter/intra regional commodity flows, a regional input-output system should be solved at a level of aggregation most closely aligned with the aggregation reported in the transportation data. While this aggregation may be insufficient for the specific purposes of the developer, it is likely that the developer knows of other unique data sources related to transportation in the sectors of particular relevance to their research and this 
data can be incorporated. For other sectors that the developer has little familiarity with, the aggregated data will probably end up providing more information than if it was used, for example, to move all subcategories of each commodity aggregate.

To illustrate how to use both of these 'rules' could complement each other, consider the following example. Suppose annual state-to-state transportation statistics were available to a developer designing an U.S. MRIO system for use in energy analysis. If this transportation data described the value of shipments within and between states on 'Food and Kindred Products', commodities as diverse as cotton and ice would belong to this industry aggregate. Suppose a particular region of an MRIO system produces food and kindred products that predominantly have similar cost structures as ice, and another region has products in this category that predominantly have similar cost structures as cotton. Using the product mix approach, the former region would end up with an aggregate food industry I-O coefficient for electricity that would be considerably higher than in the later region.

Now suppose that after doing the work of developing detailed regional output data for the product mix approach, the developer decided to keep the detail in the model they are trying to solve. Typically, this would mean that if transportation data indicated 20-percent of region I food and kindred product shipments went to region II, than a prior for each detailed commodity would have 20-percent going to region II. In solving a system with such priors, it is very likely that a substantial amount of product will be redirected, while a more aggregated system would most likely not have as much redirection. The significance of this result is illustrated in the following scenario.

Suppose an U.S. MRIO system includes regions of Florida and California, and one of the commodities modeled was 'canned fruits and vegetables'. While this is typically viewed as a 
detailed commodity category, there is a large product variety within this group, including fresh orange juice - a product almost unique to Florida. California produces a substantial share of the canned vegetables. Using the aggregated transportation data priors to move canned fruits and vegetables, both Florida and California will initially have too much canned products remaining in State. Further, from an optimization perspective, it will be very efficient to diminish or sever the bilateral flows of canned products between California and Florida. A developer specializing in the energy industry is unlikely to notice this outcome. On the other hand, using the aggregated sectors, the CA/FL trade linkage is more likely to be preserved. For most energy issues, it's not important to know that Florida and California are trading orange juice and canned vegetables, but it is important to know that the two economies have a strong direct economic linkage.

Appendix III reports an U.S. MRIO system with 51 regions and 38 sectors based on the data and approaches discussed in this section [forthcoming]. While such a system is likely to have too much industry aggregation for most practical applications, extensions of this data set using the procedures discussed above for the sectors of interest to the developer's application would be a routine extension of this approach. Evaluating the accuracy for this MRIO system is an important topic, but is beyond the scopes of present inquiry.

\section{Conclusions and Direction for Future Research}

This study constructed a mathematical programming model to estimate interregional trade patterns and input-output accounts based on an interregional accounting framework and initial estimates of interregional shipments in a national system of economic regions. The model is quite flexible in its data requirement and has desirable theoretical and empirical properties. An empirical test on the model using a 3-region, 10-sector example aggregated from version 4 
GTAP database show that the model performed remarkably well in discovering the true patterns of interregional trade from highly distorted initial estimates on interregional shipments. It shows the model may have great potential in the application of estimating and reconciliation of interregional trade flow data, which often are the most difficult part in assembling the equilibrium base year data set for interregional CGE models. In addition, solutions from the aggregated model exactly provide the data needed for a MRIO model and solution from the extended model exactly provide the data needed for an IRIO model. This will greatly reduce the data processing burden in such analysis. Therefore, application of the model will further facilitate quantitative economic analysis in regional sciences.

However, there are important questions not yet answered by the current study. First, test results from the data set aggregated from GTAP also show that our model's ability to improve the IO transaction estimates of individual regions from national average may be limited. Continuing research on the real underlying causes and ways of improvement are needed to further enhance the model's capacity as an estimating and reconciliation tool in building interregional production and trade accounts. Second, the relative importance of regional sector output, value-added, exports, imports and final demand as model input in the accuracy of a model solution is also not analyzed yet, and could be addressed with minor changes of the current model. Finally, the robustness of the model performance needs further testing by using other data sets. 


\section{Appendix A: Constraint Matrix Balancing problem}

The model is a special case of the constrained matrix-balancing problem from a mathematical perspective. It is so named because it involves the computation of the best estimate of an unknown matrix from a given matrix, with some prior information to constrain the solution set. It appears as a core structure in diverse applications. These applications include the estimation of input-output tables (Bachem and Korte, 1981; Harrigan and Buchanan, 1984; Miller and Blair, 1985; Kaneko, 1988; Nagurney, 1989; Antonello, 1990) and inter-regional trade flows in regional science (Batten, 1982; Byron et al., 1993), balancing of social/national accounts in economics (Byron, 1978; Van der Ploeg, 1982, 1984,1988; Zenios, Drud, and Mulvey, 1989; Nagurney, Kim, and Robinson, 1990), estimating interregional migration in demography (Plane, 1982), the analysis of voting patterns in political science (Johnson, Hay, and Taylor, 1982), the treatment of census data and estimation of contingency tables in statistics (Friedlander, 1961), the estimation of transition probabilities in stochastic modeling (Theil and Rey, 1966), and the projection of traffic within telecommunication and transportation networks (Florian, 1986; Klincewicz, 1989). A comprehensive survey can be found in Schneider and Zenios (1990).

Methods for matrix balancing can be classified into two broad classes -- bi-proportional scaling and optimization. The scaling methods are based on the adjustments of the initial matrix to multiplying its row and column by positive constants until the matrix is balanced. It was developed by Stone and other members of the Cambridge Growth Project (Stone et al., 1963) and is usually known as RAS. The basic method was originally applied to known row and column totals but had been extended to cases where the totals themselves are not known with certainty (Senesen and Bates, 1988). Optimization methods are based on mathematical 
programming, usually minimizing a penalty function, which measures the deviation of the candidate balanced matrix from the initial matrix subject to a set of balance condition.

The scaling methods such as RAS have been one of the most widely applied computational algorithms for the solution of the constrained matrix balancing problems. They are simple, iterative, and require minimal programming effort to implement. However, as pointed out by van der Ploeg (1982), they are not straightforward to use when including more general linear restrictions and when allowing for different degrees of uncertainty in the initial estimates and restraints. They also lack a theoretical interpretation of the adjustment process. Those aspects are crucial for an adjustment procedure to improve the information content of the balanced estimates rather than only adjusting the initial estimates mechanically. Mohr, Crown and Polenske (1987) discussed the problems encountered when the RAS procedure is used to adjust trade flow data. They pointed out that the special properties of interregional trade data increase the likelihood of non-convergence of the RAS procedure and proposed a linear programming approach that incorporate exogenous information to override the unfeasibility of the RAS problem.

Since the 1980s more and more researchers have tended to formulate constrained matrix balancing problems as mathematical programming problems (var der Ploeg, 1988, Nagurney and Robinson, 1989, Bartholdy, 1991, Byron et al., 1993), with an objective function that forces "conservatism" on the process of rationalizing $\mathrm{X}$ from the initial estimate $\mathrm{X}^{0}$. The theoretical foundation for the approach can be viewed from both the perspectives of mathematical statistics and information theory. When a quadratic penalty function is used, the solution of this mathematical programming problem gives a minimum variance unbiased linear estimate of the unknown matrix X (Byron, 1978, Van der Ploeg, 1982, 1984); while when a entropy function is 
used, its solution gives the estimate of $\mathrm{X}$ which minimizes the "information added" to $\mathrm{X}^{0}$ needed to conform to the constraints (Wilson 1970). In addition, the solution of the RAS method is equivalent to constrained entropy minimization with fixed prior row and column totals, as shown by Bregman (1967), thus can been seen as a special case of the optimization methods.

Another important advantage of mathematical programming models over scaling methods in applied matrix balancing problems is that it permits one to introduce relative degree of reliability for the initial estimates. Further, additional constraints may be imposed on the data adjustment process, such as allowing precise upper and lower bounds to be placed on unknown elements, or incorporating an associated term in the objective function to penalize solution deviations from the initial row or column total estimates when they are not known with certainty. Therefore, it provides more flexibility to the matrix balancing procedure. This flexibility is very important in terms of improving the information content of the balanced estimates.

The idea of including reliability of the initial estimate in the matrix balancing process can be traced back half a century to Richard Stone and his colleagues (1942) when they explored procedures for compiling national income accounts. Their ideas were formalized into a mathematical procedure to balance the system of accounts after assigning reliability weights to each entry in the system. The minimization of the sum of squares of the adjustments between initial entries and balanced entries in the system, weighted by the reliabilities or the reciprocal of the variances of the entries is carried out subject to linear (accounting) constraints. This approach had first been operationlized by Byron (1978) and applied to the System of National Accounts of UK by Ploeg $(1982,1984)$. Zenios and his collaborators (1989) further extended this approach to balance a large social accounting matrix in a nonlinear network-programming framework. 
Although computational burden is no longer a problem today, the difficulty of estimating the error variances with this method still remains unsolved. 


\section{Appendix B GAMS Program for the 3-region, 10-sector Example}

\section{Data processing program}

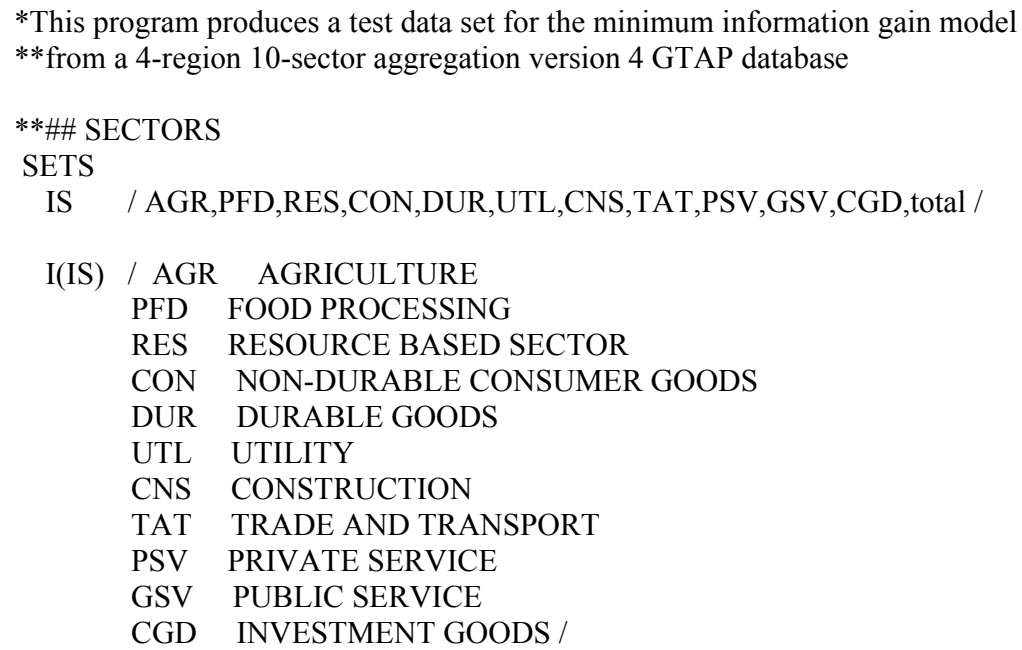


FF(IIF) / LND,ULB,SLB,CAP,NRS /

FFO(FF) / LND,ULB,SLB,CAP /

$\mathrm{FC}(\mathrm{FF}) / \mathrm{LND}, \mathrm{SLB}, \mathrm{CAP} /$

FF1(FF) / ULB,SLB,CAP /

FF2(FF) / ULB,SLB,CAP,NRS /

FL(F) / ULB,SLB /

FR(F) / LND,CAP,NRS /

$\mathrm{FB}(\mathrm{FF})$ / LND,SLB,CAP / ;

SETS

**\#\# SET FOR CET FUNCTION CONTROL

IE1(T,R) CET AGGREGATE EXPORT SECTORS

IE2(T,R) COMPETITIVE EXPORT SECTORS

/ (agr).

(USA,EEC,JPN,ROW) /

;

ALIAS (FF,FFC),(FF0,FFC0),(FF1,FFC1),(FF2,FFC2),(JJ,JJC),(FC,FCC);

ALIAS (R,RT,S,ST), (rr,ss),(I,IT), (F,FT),(FL,FLT),(T,K,KC);

SETS

**\#\# OTHER SETS

MAC MACRO VARIABLES

/ SAVE Regional savings

VDEP Capital Depreciation

VKB Capital stock in the beginning period

HTAX Household income tax /

;

SETS MISX(T,R,S) ZERO TRADE

MISE(T,R) ZERO EXPORT

MISM(T,R) ZERO IMPORT

MISQ(T,R) ZERO PRODUCTION

MISDF(FF,T,R) ZERO FACTOR DEMAND

MISVA(T,R) ZERO VALUE-ADDED

QOUTA(T,R,S) TRADE FLOWS SUBJECT IMPORT QOUTAS ;

*---------- BASIC DATA FROM GTAP GLOBAL TRADE DATA BASE ---------*

\$INCLUDE datalgtap4.DAT

$*$

-DERIVED DATA FROM THE BASIC DATA

PARAMETER

VFA(T,I,R) PRODUCER COST ON INTEMEDIATE INPUTS T BY INDUSTRY I IN REGION R AT AGENT'S PRICE

VFM(T,I,R) PRODUCER COST ON INTEMEDIATE INPUTS T BY INDUSTRY I IN REGION R AT MARKET PRICE

VOA(I,R) TOTAL PRODUCTION COST OF SECTOR I IN REGION R AT AGENT'S PRICE

VOM(I,R) TOTAL VALUE OF OUTPUT I IN REGION R AT MARKET PRICE

EVOM(F,R) TOTAL VALUE ADDED FOR FACTOR F AT MARKET PRICE

$\operatorname{VDM}(T, R) \quad$ DOMESTIC SALES OF COMMODITY T IN REGION R AT MARKET PRICE

$\operatorname{VDA}(T, R) \quad$ DOMESTIC SALES OF COMMODITY T IN REGION R AT AGENT PRICE

VPA(T,R) HOUSEHOLD EXPENDITURE ON COMMODITY T IN REGION R VALUED AT AGENT'S PRICE

$\operatorname{VPM}(\mathrm{T}, \mathrm{R}) \quad$ HOUSEHOLD EXPENDITURE ON COMMODITY T IN REGION R VALUED AT MARKET PRICE

$\operatorname{VIM}(\mathrm{T}, \mathrm{R}) \quad$ VALUE OF TOTAL IMPORTS OF COMMODITY T BY REGION R

HEXP(R) HOUSEHOLD CONSUMPTION EXPENDITURE IN REGION R

VGA $(T, R)$ GOVERNMENT HOUSE HOLD EXPENDITURE ON COMMODITY T IN REGION R AT AGENT'S PRICE

$\operatorname{VGM}(T, R) \quad$ GOVERNMENT HOUSE HOLD EXPENDITURE ON COMMODITY T IN REGION R AT MARKEY PRICE

GEXP(R) GOVERNMENT CONSUMPTION EXPENDITURE ON REGION R 
VTW(T,R,S) TRANSPORTATION COST ASSOCIATED WITH THE SHIPMENT

* OF COMMODITy T FROM REGION R TO S

ER(T,R) DIFFERENCE BETWEEN TOTAL IMPORTS AND DOMESTIC ABSORBTION

* OF IMPORT GOODS, SHOULD BE ZERO

BOT(R) BALANCE OF TRADE IN REGION R

CHECKA(T,R)

CHECKC(T,R)

VT TOTAL COST OF INTERNATIONAL TRANSPORTATION SERVICES

SAVE(R) HOUSEHOLD SAVINGS

VDEP(R) DEPRECIATION

$\mathrm{VKB}(\mathrm{R}) \quad$ CAPITAL STOCK

REGINV(R) GROSS REGIONAL INVESTMENT IN REGION R

GSAV(R) GOVERNMENT SAVING OR DEFICIT;

PARAMETERS

SAVE $(\mathrm{R}) \quad$ Expenditures on net savings (AP)

$\operatorname{VDEP}(\mathrm{R}) \quad$ Value of capital depreciation (AP)

VKB (R) Value of beginning-of-period capital stock (AP)

GTRANSO(R) GOVERNMENT SAVING OR DEFICIT

;

$\operatorname{SAVE}(\mathrm{R})=\operatorname{MACRO}(\mathrm{R}, " \mathrm{save} ")$;

$\operatorname{VDEP}(\mathrm{R})=\operatorname{MACRO}(\mathrm{R}, " \mathrm{vdep} ")$;

$\operatorname{VKB}(\mathrm{R})=\operatorname{MACRO}(\mathrm{R}, " \mathrm{kkb} ")$;

$\operatorname{VFA}(\mathrm{T}, \mathrm{I}, \mathrm{S})=\operatorname{VDFA}(\mathrm{T}, \mathrm{I}, \mathrm{S})+\operatorname{VIFA}(\mathrm{T}, \mathrm{I}, \mathrm{S})$

$\operatorname{VFM}(T, I, S)=\operatorname{VDFM}(\mathrm{T}, \mathrm{I}, \mathrm{S})+\operatorname{VIFM}(\mathrm{T}, \mathrm{I}, \mathrm{S})$;

$\operatorname{VOA}(\mathrm{I}, \mathrm{R})=\operatorname{SUM}(\mathrm{T}, \mathrm{VFA}(\mathrm{T}, \mathrm{I}, \mathrm{R}))+\mathrm{SUM}(\mathrm{F}, \mathrm{EVFA}(\mathrm{F}, \mathrm{I}, \mathrm{R}))$;

$\operatorname{VDM}(T, R)=\operatorname{VDPM}(T, R)+\operatorname{VDGM}(T, R)+\operatorname{SUM}(I, \operatorname{VDFM}(T, I, R))$;

$\operatorname{VDA}(T, R)=\operatorname{VDPA}(T, R)+\operatorname{VDGA}(T, R)+\operatorname{SUM}(I, \operatorname{VDFA}(T, I, R))$;

$\operatorname{VOM}(" C G D ", R)=\operatorname{VOA}(" C G D ", R)$;

$\operatorname{VOM}(T, S)=\operatorname{VDM}(\mathrm{T}, \mathrm{S})+\operatorname{SUM}(\mathrm{R}, \operatorname{VXMD}(\mathrm{T}, \mathrm{S}, \mathrm{R}))+\operatorname{VST}(\mathrm{T}, \mathrm{S})$;

$\operatorname{EVOM}(\mathrm{F}, \mathrm{R})=\operatorname{SUM}(\mathrm{I}, \operatorname{EVFM}(\mathrm{F}, \mathrm{I}, \mathrm{R}))$;

$\operatorname{VPA}(\mathrm{T}, \mathrm{S})=\operatorname{VDPA}(\mathrm{T}, \mathrm{S})+\operatorname{VIPA}(\mathrm{T}, \mathrm{S})$;

$\operatorname{VPM}(\mathrm{T}, \mathrm{S})=\operatorname{VDPM}(\mathrm{T}, \mathrm{S})+\operatorname{VIPM}(\mathrm{T}, \mathrm{S})$;

$\operatorname{HEXP}(\mathrm{R})=\operatorname{SUM}(\mathrm{T}, \mathrm{VPA}(\mathrm{T}, \mathrm{R}))$;

$\operatorname{VGA}(\mathrm{T}, \mathrm{S})=\operatorname{VDGA}(\mathrm{T}, \mathrm{S})+\operatorname{VIGA}(\mathrm{T}, \mathrm{S})$;

$\operatorname{VGM}(\mathrm{T}, \mathrm{S})=\operatorname{VDGM}(\mathrm{T}, \mathrm{S})+\operatorname{VIGM}(\mathrm{T}, \mathrm{S})$;

$\operatorname{GEXP}(\mathrm{R})=\operatorname{SUM}(\mathrm{T}, \operatorname{VGA}(\mathrm{T}, \mathrm{R}))$

SAVE(R) = MACRO(R,"SAVE");

$\operatorname{VDEP}(\mathrm{R})=\operatorname{MACRO}(\mathrm{R}, " \mathrm{VDEP} ")$;

$\mathrm{VKB}(\mathrm{R})=\operatorname{MACRO}(\mathrm{R}, " \mathrm{VKB} ")$;

$\operatorname{VTW}(T, R, S)=\operatorname{VIWS}(T, R, S)-\operatorname{VXWD}(T, R, S)$;

BOT(R) = SUM(T,VST(T,R))+ SUM((T,S), VXWD(T,R,S)) - SUM((T,S), VIWS(T,S,R));

$\mathrm{VT}=\mathrm{SUM}((\mathrm{T}, \mathrm{S}, \mathrm{R}), \mathrm{VTW}(\mathrm{T}, \mathrm{R}, \mathrm{S}))$;

* DISPLAY VDM, VFA, VFM, VPA,VPM,VGA,VGM;

DISPLAY VOA,VOM;

* DISPLAY EVOM,HEXP,GEXP,VTW, BOT,VT;

PARAMETER

PTAX(I,R)

VALUE OF PRODUCT TAX

DPTAX $(T, R) \quad$ VALUE OF CONSUMPTION TAX OF DOMESTIC GOODS BY HOUSEHOLD

IPTAX $(T, R) \quad$ VALUE OF CONSUMPTION TAX OF IMPORTS BY HOUSEHOLD

DGTAX $(T, R) \quad$ VALUE OF CONSUMPTION TAX OF DOMESTIC GOODS BY GOVERNMENT

IGTAX(T,R) VALUE OF CONSUMPTION TAX OF IMPORTS BY GOVERNMENT

DFTAX(T,I,R) VALUE OF CONSUMPTION TAX OF DOMESTIC GOODS BY FIRMS

IFTAX(T,I,R) VALUE OF CONSUMPTION TAX OF IMPORTS BY FIRMS

XTAX(T,R,S) VALUE OF EXPORT TAX

MTAX(T,S,R) VALUE OF TARRIFF 


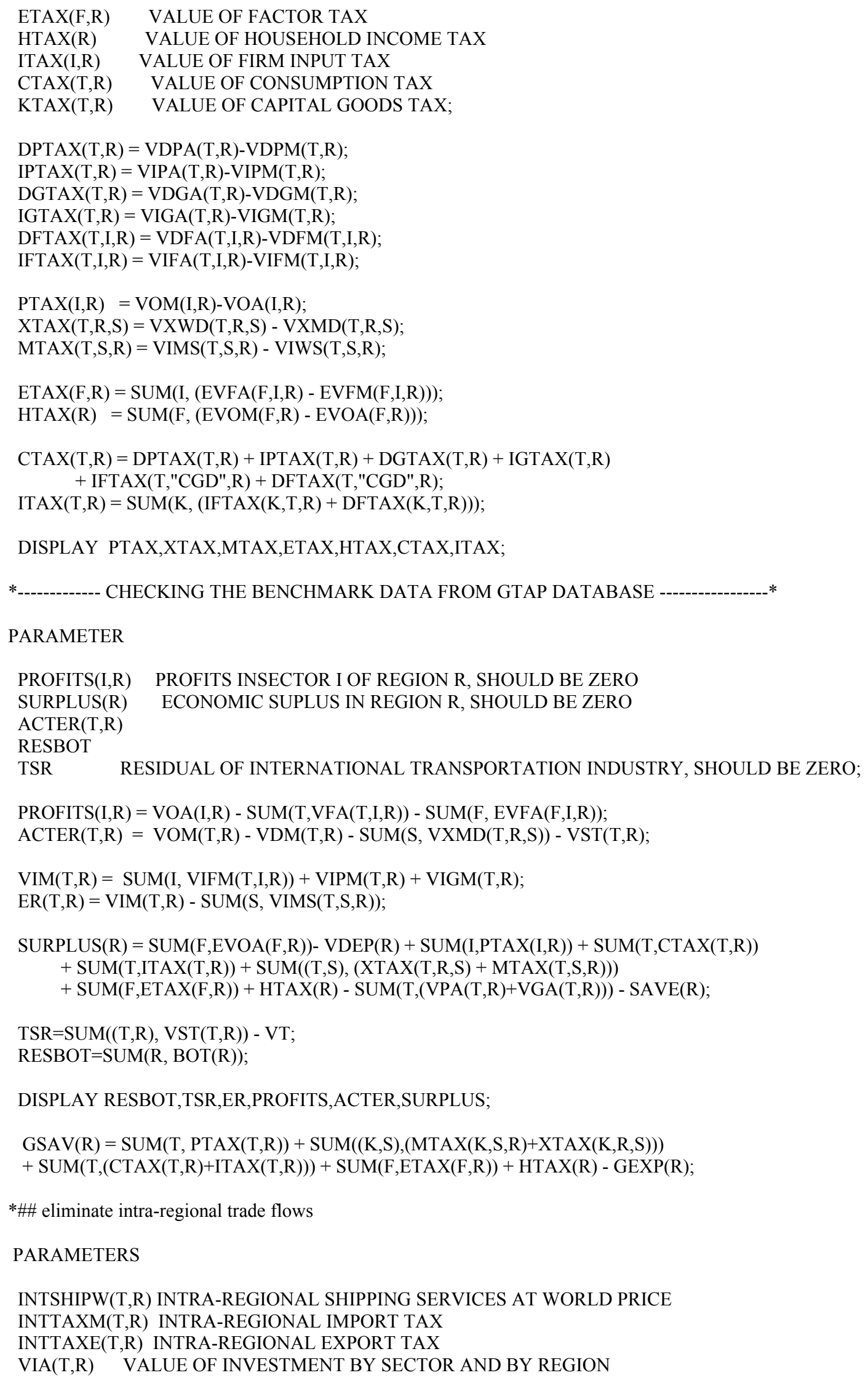




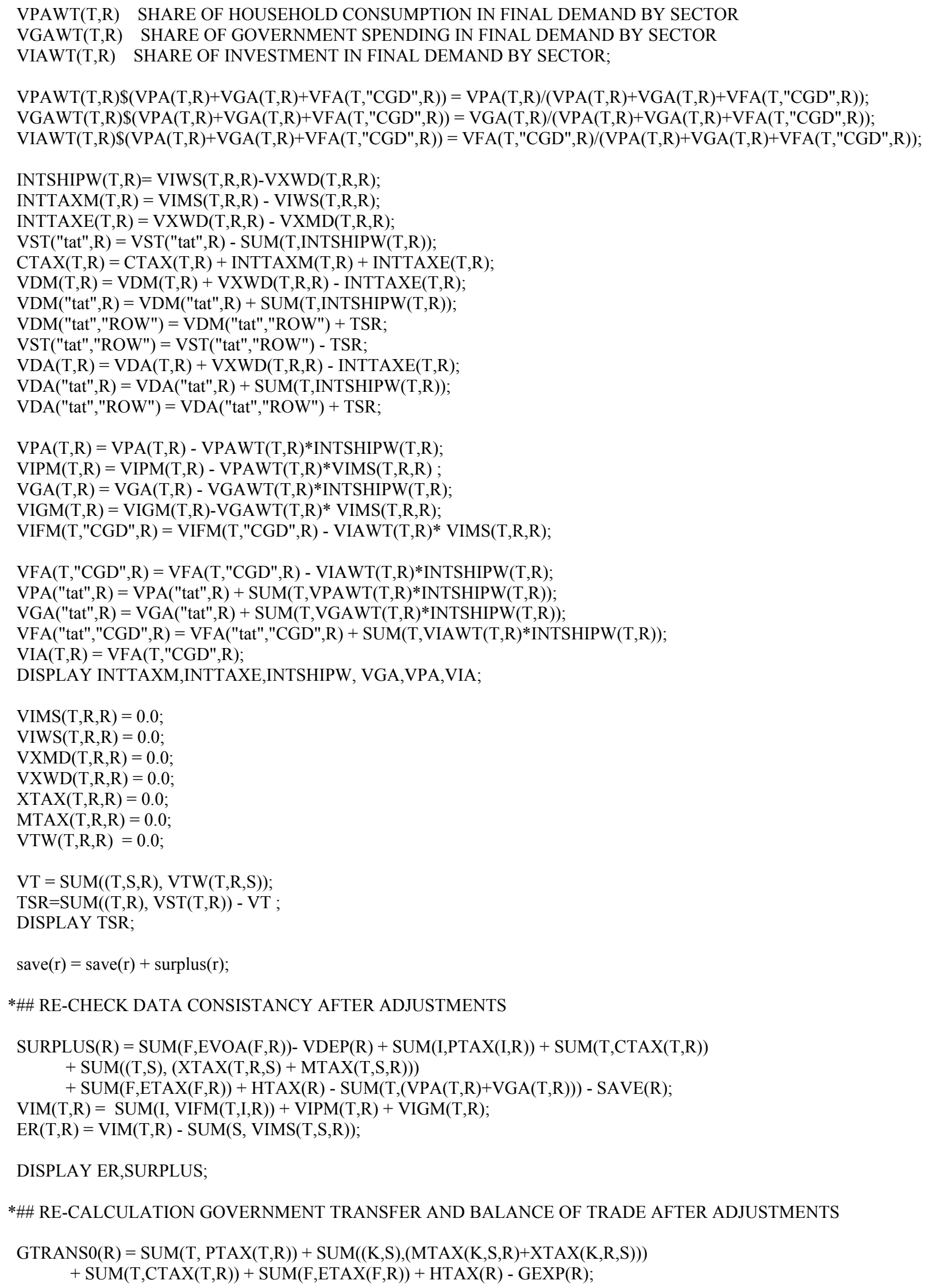


BOT $(R)=\operatorname{SUM}(T, \operatorname{VST}(T, R))+\operatorname{SUM}((T, S), \operatorname{VXWD}(T, R, S))-\operatorname{SUM}((T, S), \operatorname{VIWS}(T, S, R))$;

*-------------CONSTRUCTION OF SOCIAL ACCOUNTING MATRIX---------------*

SETS

SI / ACT,COMD,FLD,FLB,FK,ENT,PH,GV,KA,WT,ITR,TOTAL/

SIT(SI) /TOTAL/

$\mathrm{S} 1(\mathrm{SI}) / \mathrm{ENT}, \mathrm{GV}, \mathrm{PH}, \mathrm{KA}, \mathrm{WT}, \mathrm{ITR} /$

$\mathrm{SSI}(\mathrm{S} 1) / \mathrm{WT}, \mathrm{ITR} /$

SI1(SI);

ALIAS(SI1,SI2);

PARAMETER

SAM(R,SI,SI) SOCIAL ACCOUNTING MATRIX

RES(SI,R) RESIDUAL OF REVENUE AND EXPENDITURE, SHOULD BE ZERO;

$\operatorname{SI} 1(\mathrm{SI})=\mathrm{NOT} \operatorname{SIT}(\mathrm{SI})$

* FIRST BLOCK: ACTIVITIES. DOMESTIC SUPPLY,EXPORT SUBSIDY, EXPORTS AT MP

* EXPORTS FOR INTERNATIONAL TRANSPORTATION.

$\operatorname{SAM}(\mathrm{R}, " A C T ", " C O M D ")=\operatorname{SUM}(\mathrm{T}, \mathrm{VDM}(\mathrm{T}, \mathrm{R}))$;

$\operatorname{SAM}(\mathrm{R}, " A C T ", " G V ")=-\operatorname{SUM}((\mathrm{T}, \mathrm{S}),(\mathrm{VXWD}(\mathrm{T}, \mathrm{R}, \mathrm{S})$ - VXMD(T,R,S)));

SAM(R,"ACT", "WT") = SUM((T,S), VXWD(T,R,S));

SAM(R,"ACT","ITR") = SUM(T,VST(T,R));

* SECOND BLOCK: COMMODITIES. INTERMEDIATE DEMAND,HOUSEHOLD CONSUMPTION, * GOVERNMENT CONSUMPTION,INVESTMENT.

$\operatorname{SAM}(\mathrm{R}, " \mathrm{COMD}$, ,ACT") = SUM((T,K), VFA(T,K,R));

$\operatorname{SAM}(\mathrm{R}, " \mathrm{COMD}$, "PH") = SUM(T, VPA(T,R));

$\operatorname{SAM}(\mathrm{R}, " \mathrm{COMD}$, "GV") = SUM(T, VGA(T,R));

SAM(R,"COMD","KA") = SUM(T, VFA(T,"CGD",R));

* THIRD BLOCK: VALUE ADDED

$\operatorname{SAM}(R, " F L D ", " A C T ")=\operatorname{SUM}(\mathrm{I}$, EVFM("LND",I,R));

SAM(R,"FLB","ACT") = SUM(I, EVFM("ULB",I,R)) + SUM(I, EVFM("SLB",I,R));

SAM(R,"FK","ACT") = SUM(I, EVFM("CAP",I,R)) + SUM(I, EVFM("NRS",I,R));

* FOURTH BLOCK: ENTERPRISE. CAPITAL INCOME AND DEPRECIATION.

$\operatorname{SAM}(\mathrm{R}$, "ENT","FK") = EVOM("CAP",R) + EVOM("NRS",R);

$\operatorname{SAM}(\mathrm{R}, " E N T ", " P H ")=\operatorname{VDEP}(\mathrm{R})$;

* FIFTH BLOCK: HOUSEHOLDS. INCOME FROM FACTORS.

$\operatorname{SAM}(\mathrm{R}, " P H "$, "FLD") =EVOM("LND",R);

$\operatorname{SAM}(\mathrm{R}, " P H ", " F L B ")=$ SUM(T,EVFM("ULB",T,R)) + SUM(T,EVFM("SLB",T,R));

$\operatorname{SAM}(\mathrm{R}, " \mathrm{PH}$,,ENT") = EVOM("CAP",R) + EVOM("NRS",R);

* SIXTH BLOCK: GOVERNMENT. INDIRECT TAX,TARIFFS,FACTOR TAX,CAPITAL RETURN

* HOUSEHOLD TAX,NET TRANSFER AMONG GOVERNMENT.

$\operatorname{SAM}(\mathrm{R}, " G V ", " F L D ")=\operatorname{ETAX}(" L N D ", R) ;$

$\operatorname{SAM}(R, " G V ", " F L B ")=\operatorname{ETAX}(" U L B ", R)+\operatorname{ETAX}(" S L B ", R)$;

$\operatorname{SAM}(R, " G V ", " F K ")=\operatorname{ETAX}(" C A P ", R)+\operatorname{ETAX}(" N R S ", R)$;

$\operatorname{SAM}(\mathrm{R}, " \mathrm{GV},, \mathrm{PH} ")=\operatorname{HTAX}(\mathrm{R})$ - GSAV(R); 


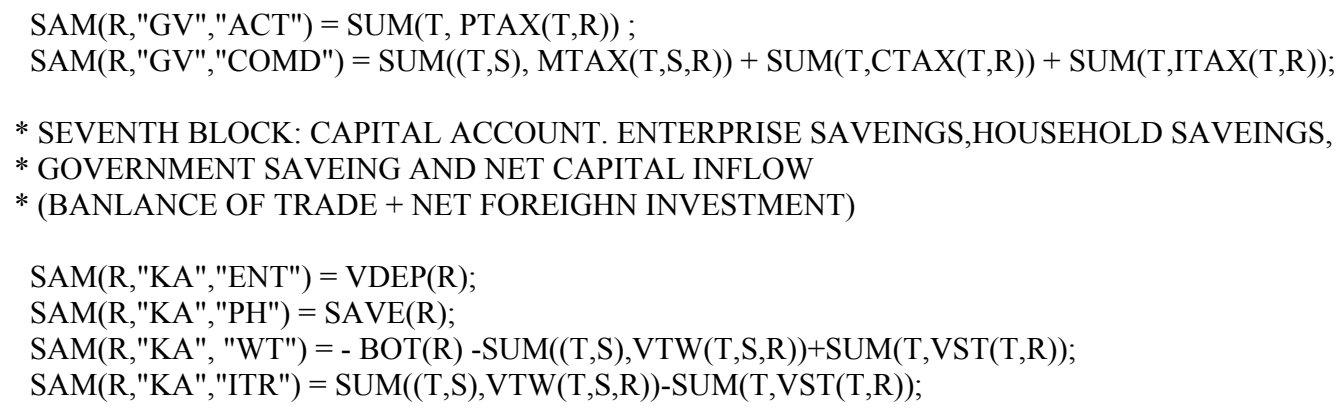




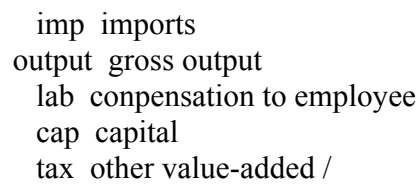


ss1 ;

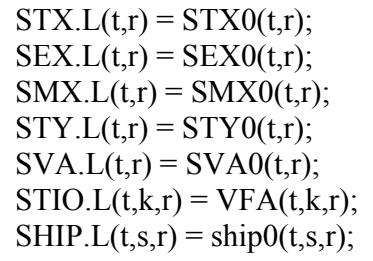

OPTIONS NLP=pathnlp;

DATAbal.OPTFILE $=1$;

SOLVE databal USING NLP MINIMIZING SS1;

$\mathrm{NX}(\mathrm{t}, \mathrm{k})=\mathrm{SUM}(\mathrm{rr}, \mathrm{STIO} \cdot \mathrm{L}(\mathrm{t}, \mathrm{k}, \mathrm{rr}))$ 


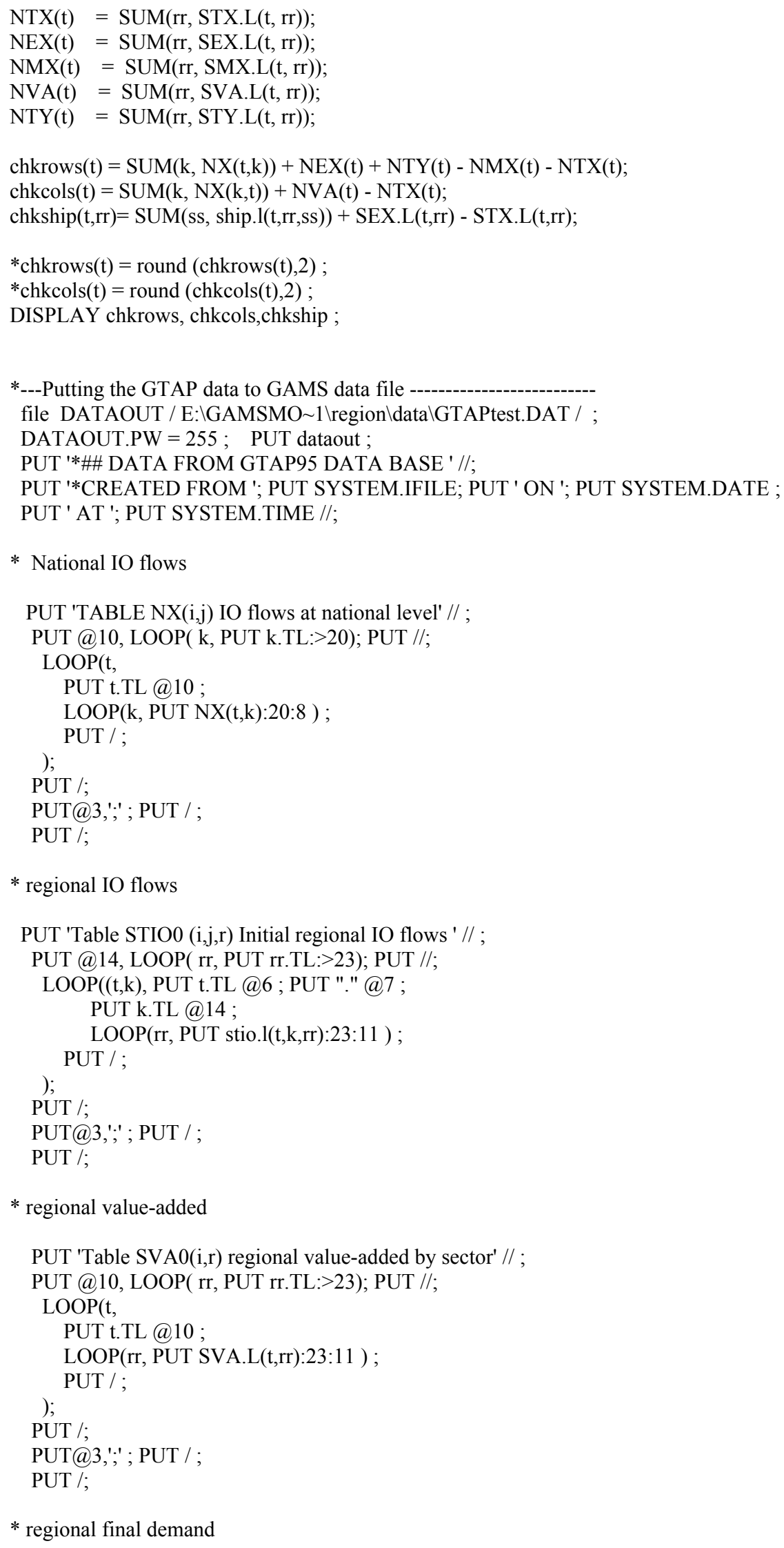




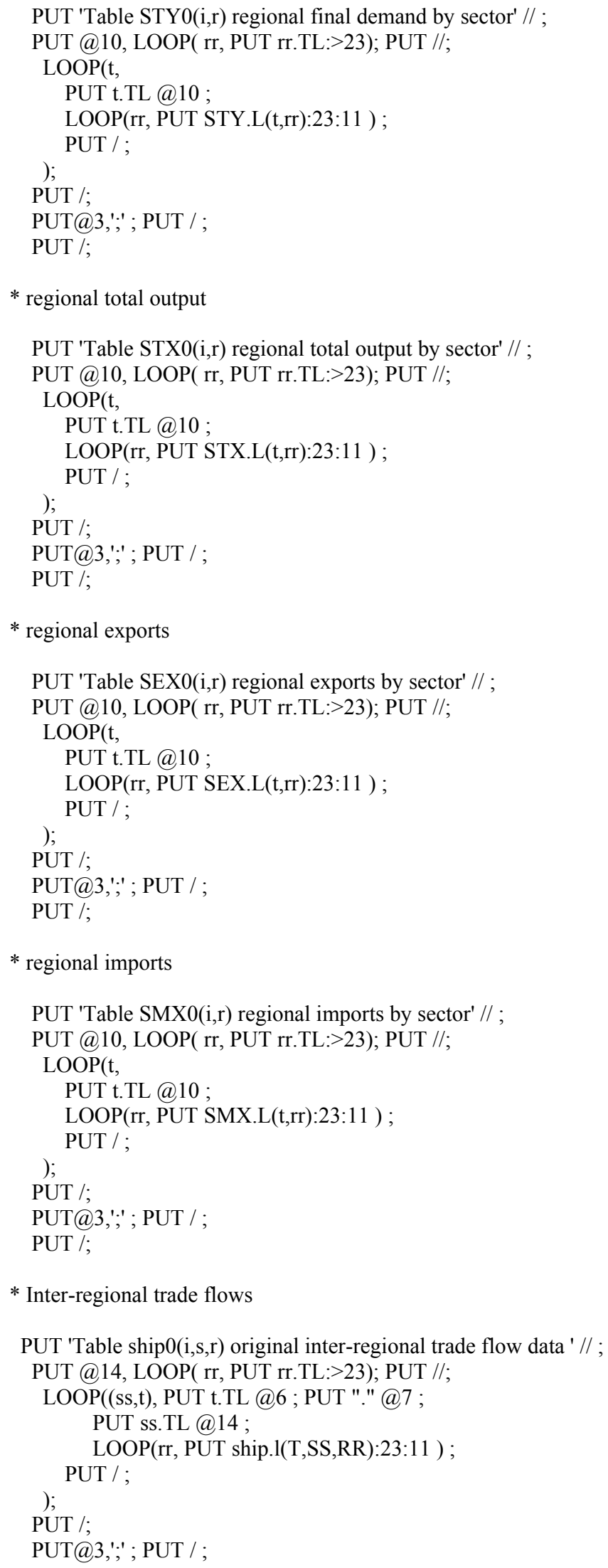


PUT /;

\section{The minimum information gain model program}

\$OFFSYMLIST OFFSYMXREF

*\#\# This program implement minimum information gain procedure

*\#\# to estimate interregional, interindustry transaction flows in a national system

*\#\# of regions based on a regional accounting framework and limited regional statistic

*\#\# data. The complete national I0 table, regional sectoral data on gross output,

*\#\# value-added, exports, imports and final demand are used as inputs to generate

*\#\# interregional pattern of shipment from limited information.

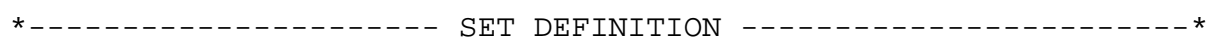

\$INCLUDE setgtap.inc

READ US 1997 BENCHMARK IO TABLE FROM BEA _........ *

PARAMETERS

*NX( $i, j) \quad$ National I0 flows (input from sector $i$ to sector $j$ )

NTX(i) National total gross output in sector $i$

NEX(i) National exports in sector $i$

$\operatorname{NMX}(i) \quad$ National imports in sector $i$

NTY(i) National total final demand for sector $i$

NVA(i) National value-added in sector $i$

chkrows(i) Row residuals

chkcols(i) Column residuals

chkship $(i, r)$ residual of shipment ;

\$INCLUDE data/GTAPTEST.dat

$\operatorname{NX}(i, j)=\operatorname{SUM}(r, \operatorname{STIOO}(i, j, r)) ;$

$\operatorname{NTX}(i)=\operatorname{SUM}(r, \operatorname{STX} \Theta(i, r)) ;$

$\operatorname{NEX}(i) \quad=\operatorname{SUM}(r, \operatorname{SEX} \odot(i, r))$;

$\operatorname{NMX}(i) \quad=\operatorname{SUM}(r, \operatorname{SMX} \odot(i, r))$;

$\operatorname{NVA}(i) \quad=\operatorname{SUM}(r, \operatorname{SVAO}(i, r))$;

$\operatorname{NTY}(i)=\operatorname{SUM}(r, \operatorname{STYO}(i, r))$;

*\# Check balance of the national Io table

$\operatorname{chkrows}(i)=\operatorname{SUM}(j, \operatorname{NX}(i, j))+\operatorname{NEX}(i)+\operatorname{NTY}(i)-\operatorname{NMX}(i)-\operatorname{NTX}(i)$;

$\operatorname{chkcols}(i)=\operatorname{SUM}(j, N X(j, i))+\operatorname{NVA}(i)-\operatorname{NTX}(i)$;

$\operatorname{chkship}(i, r)=\operatorname{SUM}(s, \operatorname{ship} \odot(i, r, s))+\operatorname{SEX} \odot(i, r)-\operatorname{STX} \odot(i, r)$;

${ }^{*} \operatorname{chkrows}(\mathrm{t})=$ round $(\operatorname{chkrows}(\mathrm{t}), 2) ;$

${ }^{*} \operatorname{chkcols}(t)=\operatorname{round}(\operatorname{chkcols}(t), 2) ;$

DISPLAY chkrows, chkcols, chkship ;

*\#\# assign coefficient in the objective function for QP

parameters

$\operatorname{TXQ}(i, r)$

$\operatorname{TYQ}(i, r)$

$\operatorname{EXQ}(i, r)$

$\operatorname{MXQ}(i, r)$

$\operatorname{VAQ}(i, r)$

$S P Q(i, s, r)$

$\operatorname{IOQ}(i, j, r)$; 


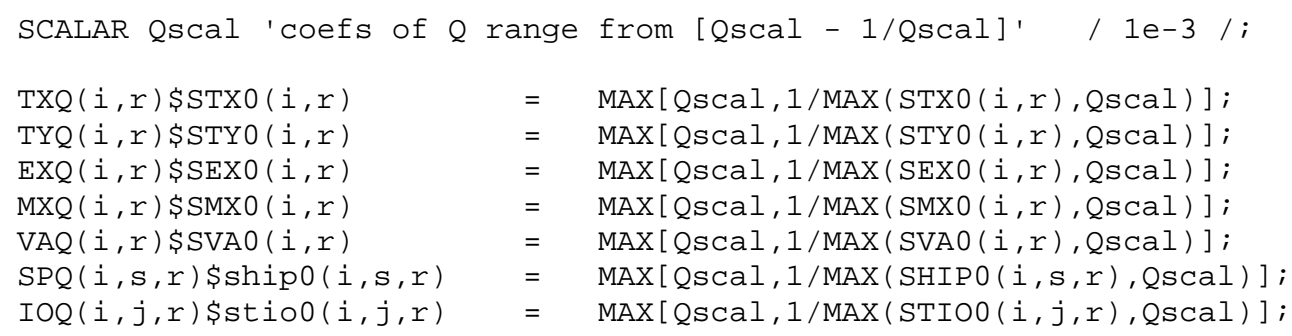

\section{PARAMETERS}

$\operatorname{checka}(i, r)$ checkc $(i, r)$ 
rowbal $(i, r)$ Sum of intermediate and final demand equals shipment from all region plus imports shipbal $(i, r)$ Sum of shipment to all region and export equals the region's output

$\operatorname{NIOBAL}(i, j)$ Sum IO flows from sector $i$ to sector $j$ for all state equal the national totals NFDBAL(i) Sum final demand of commodity $i$ delivered by each state equal to national totals NMAKBAL( $i) \quad$ Sum of output for sector $i$ by each state equal to national output in sector $i$ NEXPBAL(i) Sum of exports of commodity $i$ by each state equal to total national exports NIMPBAL( $i) \quad$ Sum of imports of commodity $i$ by each state equal to total national imports NVABAL(i) Sum of value-added of each state equal to total national exports

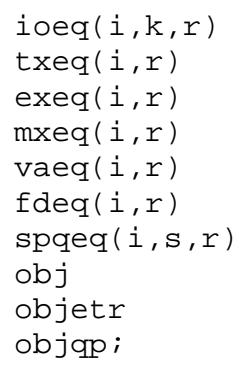




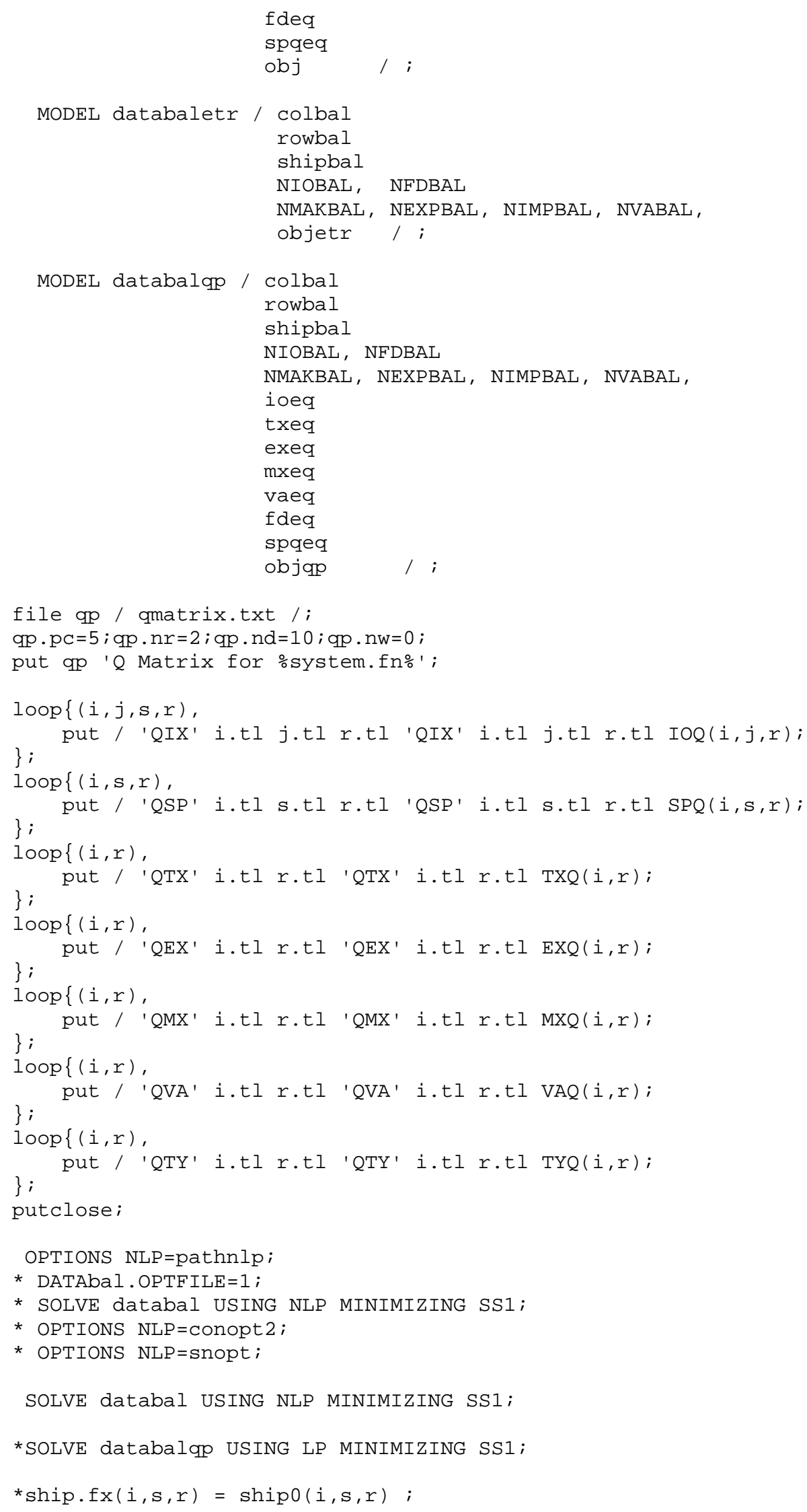




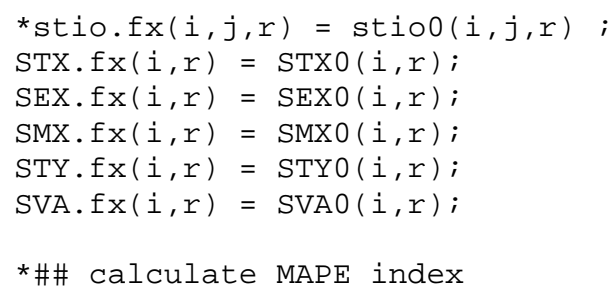

DISPLAY MAPE, MAPERS, MAPERr, MAPEI, MAPEU ; 


\section{References}

Antonello, Paola (1990) " Simultaneous Balancing of Input-Output Tables at Current and Constant Prices with First Order Vector Autocorrelated Errors." Economic Systems Research, Vol. 2, No. 2, pp. 157-171.

Bachem, Achim and Bernhard Korte (1981) Mathematical Programming and Estimation of Input-Output Matrices, Report WP78102, University of Bonn.

Bartholdy, Kasper (1991) "A Generalization of the Friedlander Algorithm for Balancing of National Accounts Matrices." Computer Science in Economics and Management Vol. 2, pp. 163174.

Batten, F. David (1982) " The Interregional Linkages Between National and Regional InputOutput Models." International Regional Science Review, Vol. 7, pp. 53-67.

Bregman, L. M. (1967) "Proof of the Convergence of Sheleikhovskii's method for a problem with transportation constraints." USSR Computational Mathematics and Mathematical Physics, Vol. 1, No. 1 pp. 191-204.

Brook, A., David Kendrick and Alexander Meeraus (1988) GAMS a User's Guide, The Scientific Press.

Byron, R. P. (1978) "The Estimation of Large Social Account Matrix." Journal of Royal Statistical Society, A, Vol.141, Part 3, pp. 359-367.

Byron, R. P., P.J. Crossman, J.E. Hurley and S.C. Smith (1993) " Balancing Hierarchial regional Accounting Matrices." Paper presented to the International Conference in memory of Sir Richard Stone, National Accounts, Economic Analysis and Social Statistics, Siena, Italy, October 17-20, 1993.

Florian, M. (1986) "Nonlinear Cost Network Models in Transportation Analysis." Mathematical Programming Study, Vol. 26, pp. 167-196.

Friedlander, D. (1961) "A technique for estimating contingency table, given the marginal totals and some supplementary data." Journal of the Royal Statistical Society, A. Vol.124, Part 3, pp. 412-420.

Golan, Amos, George Judge, and Sherman Robinson (1994) "Recovering Information From Incomplete or Partial Multisectoral Economic Data." The Review of Economics and Statistics, Vol. LXXVI, No. 3, pp. 541-549.

Government Services Administration, Federal Procurement Data Services http://fpdsweb1.gsa.gov/fpdsweb/fpdsgeosearch1 
Harrigan, J. Frank (1990) " The Reconciliation of Inconsistent Economic Data: the Information Gain." Economic System Research, Vol.2, No.1, pp. 17-25.

Harrigan, J. Frank and Iain Buchanan (1984) " A Quadratic Programming Approach to InputOutput Estimation and Simulation." Journal of Regional Science, Vol. 24, No.3, 1984.

Isard, Walter, Iwan Azis, Matthew P. Drennan, Ronald E. Miller, Sidney Saltzman, and Erik Thorbecke (1998) "Methods of Interregional and Regional Analysis" Ashgate Publishing Company.

Johnston, R.J., A.M. Hay, and P. J. Taylor (1982) "Estimating the Sources of Spatial Change in Election Results: A Multipropotional Matrix Approach." Environment and Planning, A, Vol. 14 pp. 951-962.

Kaneko, Yukio (1988) "An Empirical Study on Non-survey Forecasting of the Input Coefficient Matrix in a Leontief Model." Economic Modeling, No.1, pp. 41-48.

McDougall, R.A., A. Elbehri, and T.P. Truong (1998). Global Trade Assistance and Protection: The GTAP 4 database, Center for Global Trade Analysis, Purdue University

Miller, R. E. and P.D. Blair (1985) Input-Output Analysis: Foundations and Extensions. Prentice Hall, Englewood Cliffs, New Jersey.

Mohr, M., W. H. Crown and K. R. Polenske (1987) "A Linear Programming Approach to Solving Infeasible RAS Problems." Journal of Regional Sciences, Vol. 27, No.4, pp. 587-603.

Nagurney, A. (1989) " An Algorithm for the solution of a quadratic programming problem, with application to constrained matrix and spatial price equilibrium problems. " Environment and Planning, A, Vol. 21, pp. 99-114.

Nagurney, A. and A.G. Robinson (1989) "Equilibration Operators for the Solution of Constrained Matrix Problems." Operations Research Center Working Paper, OR 196-89, Operations Research Center, MIT, Cambridge, Mass. Nagurney, A., Dae-Shik Kim and A.G. Robinson (1990) "Serial and Parallel Equilibration of Large-Scale Constrained Matrix Problems with Application to the Social and Economic Sciences." The International Journal of Supercomputer Applications, Vol. 4, No. 1, pp. 49-71.

Plane, D.A. (1982) "An Information Theoretic Approach to the Estimation of Migration Flows. " Journal of Regional Sciences, Vol. 22, pp. 441-456.

Polenske, Karen R. (1980) “The U.S. Multiregional Input-Output Accounts and Model." Lexington, Mass.: Lexington Books.

Schneider, Michael H., and Stavros A. Zenios, (1990) "A Comparative Study of Algorithms for Matrix Balancing." Operations Research, Vol. 38, No. 3, pp. 439-455. 
Senesen, G. and J. M. Bates (1988) "Some Experiments with Methods of Adjusting Unbalanced Data Matrices." Journal of the Royal Statistical Society, A. Vol.151, Part 3, pp. 473-490.

Stone, R. (1982)

Stone, R. (1984) "Balancing the national accounts. The adjustment of initial estimates: a neglected stage in measurement." in A. Ingham and A.M. Ulph eds. Demand, Equilibrium and Trade, Macmillan, London.

Stone, R. Bates, J. M. and Bacharach, M (1963) A programme for Growth, Vol. 3 Input-Output Relationship 1954-1966, Chapman and Hall, London.

Stone, R. Champernowne, D.G. and Meade, J.E. (1942) " The precision of national income estimates." Review of Economic Studies, Vol. 9, No. 2, pp.110-125.

Stone, R. (1988) "Progress in Balancing the National Accounts." in Ironmonger, D., Perkins, J.O.N. and van Hoa T. eds. National Income and Economic Progress, Essays in Honor of Colin Clark, Macmillan.

Theil, Henri and G. Ray (1966) "A quadratic Programming Approach to the Estimation of Transition Probabilities." Management Sciences, No. 12, 714-721.

van der Ploeg, F. (1982) "Reliability and the adjustment of Sequences of Large Economic Accounting Matrices." Journal of the Royal Statistical Society, A. Vol.145, pp 169-194.

van der Ploeg, F. (1984) "General Least Squares Methods for Balancing Large Systems and tables of National Accounts." Review of Public Data Use, Vol. 12, pp. 17-33.

van der Ploeg, F. (1985) "Econometrics and inconsistencies in the national accounts." Economic Modeling, No. 1, pp. 8-15.

van der Ploeg, F. (1988) " Balancing Large Systems of national Accounts " Computer Science in Economics and Management Vol.1, pp. 31-39.

Weale, M. R. (1985) "Testing Linear Hypotheses on National Account data." Review of Economics and Statistics, Vol. 67, pp. 685-689.

Weale, M. R. (1989) Asymptotic maximum-likelihood estimation of national income and expenditure, Cambridge, mimeo.

Wilson, A. G. (1970) Entropy in Urban and Regional Modeling, Pion Limited, London.

Zenios, A. Stavros, Arne Drud and John M. Mulvey (1989) " Balancing Large Social Accounting Matrices with Nonlinear Network Programming." NETWORKS, Vol. 19, pp. 569-585. 